\title{
Abflussentstehung - wie aus Niederschlag Abfluss wird
}

4.1 Grundprinzipien und wesentliche Einflussgrößen - 62

4.2 Bestimmung der abflusswirksamen

Niederschlagshöhe -62

4.3 Das Runoff-Curve-Number-Verfahren - 63

4.4 Modellregen für den ländlichen Hochwasserschutz - 74

4.5 Ansatzpunkte zur Reduktion des Abflussvolumens - 78

Literatur - 90 


\subsection{Grundprinzipien und wesentliche Einflussgrößen}

Oberflächenabfluss entsteht durch Regen, wenn die Rückhaltemöglichkeiten auf Pflanzen und Bodenoberfläche erschöpft sind und die Infiltrationsrate kleiner als die Regenintensität wird. Oberflächenabfluss durch Schneeschmelze wird hier nicht behandelt. Die Rückhaltemöglichkeiten von Pflanzen und Bodenoberfläche einschließlich Mulch sind begrenzt (wenige Millimeter). Daher kommt der Infiltrationsrate besondere Bedeutung zu. Sie sinkt grundsätzlich während eines Regens, da das Wasser einen immer größeren Weg im Boden zurücklegen muss und da die Bodenoberfläche zunehmend verschlämmt. Wichtige, ereignisspezifische Einflussgrößen der Infiltration sind die Menge und Intensität des Regens, der verfügbare Speicherraum des Bodens und die Widerstandsfähigkeit der Bodenoberfläche gegenüber Verschlämmung. Die Regenintensität kann nicht beeinflusst werden. Der Speicherraum im Boden hängt von der Korngrößenund Porenverteilung und der Bodenfeuchte ab. Im Sommerhalbjahr ist er durch die Transpiration der Pflanzen meist größer als außerhalb der Vegetationsperiode. Die Verschlämmung kann durch Bodenbedeckung und stabile Bodenaggregate verzögert werden. Die Einflussmöglichkeiten auf die Abflussbildung sind daher in erster Linie auf die Landnutzung und (insbesondere auf landwirtschaftlichen Flächen) die "Gestaltung" der Bodenoberfläche, d. h. die Bedeckung und die Bodenbearbeitung, beschränkt.

\subsection{Bestimmung der abflusswirksamen Niederschlagshöhe}

Angesichts der zahlreichen Einflussgrößen ist eine genaue Prognose des abfließenden Teils des Niederschlags selbst mit den besten Modellen nicht möglich. Um für planerische
Fragen mit überschaubarem Aufwand die Abflussreaktion abzuschätzen, haben sich daher stark vereinfachte Verfahren etabliert. Sie beschränken sich auf wesentliche Mechanismen und klammern die Dynamik vieler Prozesse aus.

$\mathrm{Zu}$ den wichtigsten etablierten Ansätzen zählen Korrelationsmethoden wie Koaxialdiagramme [1, 2], das Abflussbeiwertverfahren, die Horton-Gleichung [3], der Ansatz von Lutz [4] sowie das international weit verbreitete Curve-Number-Verfahren des amerikanischen Soil Conservation Service (SCS) $[5,6]$, aus denen zahlreiche Adaptionen abgeleitet wurden [7-9]. Sie erlauben es, anhand historischer Regenmessungen oder mittels synthetischer Modell- und Bemessungsregen den abfließenden Teil des Niederschlags (abfluss-effektiver Niederschlag $\mathrm{N}_{\text {eff }}$ ) eines Gebietes abzuschätzen, der wesentlich für die Planung von Wasserrückhaltemaßnahmen ist. Aus ihm lässt sich durch Multiplikation mit der Einzugsgebietsfläche $\left(\mathrm{A}_{\mathrm{EZG}}\right)$ das Abflussvolumen (Q) und unter Berücksichtigung der Fließzeit die Scheitelhöhe $\left(\mathrm{q}_{\mathrm{p}}\right)$ einer Abflusswelle abschätzen. Praxisleitfäden zur Anwendung der genannten Methoden existieren in Deutschland seit den 1980er-Jahren [10, 11]. Vor- und Nachteile der verschiedenen Ansätze werden unter anderem von [12-14] diskutiert. Empfohlen und genauer vorgestellt wird hier das CurveNumber-Verfahren, da es einfach, etabliert und hinreichend genau ist [15]. Curve Number werden im Folgenden als CN-Werte und das Verfahren mit CN-Verfahren bezeichnet. Als Alternative ist im $>$ Anhang 8.5 das Verfahren von Lutz beschrieben, das in einigen Bundesländern in Deutschland verwendet wird.

Der Fokus dieses Buches liegt auf der Berechnung des höchsten Abflussscheitels, da hier gleichzeitig die höchsten Wasserstände auftreten und Maßnahmen zur Hochwasserminderung üblicherweise an Ihrem Potential zur Reduktion des Wasserstands gemessen werden. Da die höchsten Abflussraten in kleinen Gebieten in der Regel bei 
kurzen Regen mit hohen Intensitäten auftreten, wird hier das Verfahren vor allem für solche Fälle beschrieben. Das Verfahren lässt sich aber ebenso für andere Fragen anwenden; dann sind aber andere Regen zu betrachten. Viele Fragen beziehen sich eher auf das Abflussvolumen als auf die Abflussrate, z. B. wenn es um die Belastung von Gewässern mit gelöstem Phosphat geht oder um die Frage, wie viel Wasser der landwirtschaftlichen Fläche verloren geht und damit für die Ertragsbildung fehlt. Im Gegensatz zur maximalen Abflussrate wird das Abflussvolumen umso größer, je mehr Niederschlag fällt. Daher sind für diese Fälle mehr die langandauernden Niederschläge von Bedeutung und nicht mehr die kurzen, hochintensiven. Auch auf diese Anwendungen des $\mathrm{CN}$-Modells wird im Folgenden eingegangen, wenn auch wesentlich kürzer.

\subsection{Das Runoff-Curve-Number- Verfahren}

Das CN-Verfahren zur Abflussprognose für Einzelereignisse wurde vom amerikanischen Soil Conservation Service (SCS) in der ersten Hälfte des 20. Jahrhunderts in kleinen, landwirtschaftlichen Einzugsgebieten in den USA abgeleitet. Hier werden nach einer Beschreibung des Verfahrens ein Anwendungsbeispiel gezeigt und verbesserte Modellparameter vorgestellt, die die Abflussprognose unter deutschen klimatischen und landwirtschaftlichen Bedingungen verbessern. Das Verfahren erlaubt es, eine Vielzahl von Einflüssen zu berücksichtigen. Für den normalen Planungsfall wird es häufig ausreichen, - Gl. 4.1 und 4.2 und die Werte aus - Tab. 4.2 zu verwenden. Es werden aber zusätzliche Gleichungen angegeben, wenn Besonderheiten berücksichtigt werden sollen. Nähere Details zu dem Verfahren sind zu finden in $[5,6]$.
Die Spannweite möglicher Abflussanteile reicht vom vollständigen Abfluss bis zum völligen Fehlen eines Abflusses. Dem ersten Fall wird ein CN-Wert von 100 zugewiesen. Dieser Fall ist bei versiegelten Flächen nahezu, aber auch bei offenen Gewässern gegeben. Im zweiten Fall, wenn selbst bei einem unendlich langen Regen kein Abfluss auftritt, die Gebietsretention also unendlich groß ist, wird $\mathrm{CN}=0$ (dies ist nur bei Meeren gegeben). Zwischen den beiden Extremfällen, $\mathrm{CN}=0$ und $\mathrm{CN}=100$, liegen alle Möglichkeiten.

Die maximal mögliche Retention $S$ (in $\mathrm{L} \mathrm{m}^{-2}=\mathrm{mm}$ ), die erst bei einem unendlich langen Regen ausgeschöpft wird, berechnet sich aus dem CN-Wert nach:

$$
S=254 \cdot\left(\frac{100}{C N}-1\right)
$$

Bei Regen, die nicht unendlich lange dauern, wird nur ein Teil dieser Maximalretention ausgenützt. Der übrige Teil des Regens ist der abflusswirksame Niederschlag $\mathrm{N}_{\text {eff }}$ (ebenfalls in $\mathrm{mm})$ :

$$
\begin{array}{ll}
N_{\text {eff }}=\frac{(N-0,2 \cdot S)^{2}}{N+0,8 \cdot S} & \text { für } N>0,2 \cdot S \\
N_{\text {eff }}=0 & \text { für } N \leq 0,2 \cdot S
\end{array}
$$

Anmerkung: In den meisten Publikationen wird das Ergebnis dieser Gleichung mit Q und nicht mit $\mathrm{N}_{\text {eff }}$ bezeichnet. Hier wird aus Gründen der Konsistenz $\mathrm{N}_{\text {eff }}$ verwendet. So bleibt Q der Abflusssumme eines Einzugsgebietes (Wellenvolumen) vorbehalten, das sich aus der Multiplikation von $\mathrm{N}_{\text {eff }}$ mit der Einzugsgebietsfläche $A_{\text {EZG }}$ ergibt ( $\triangleright$ Gl. 2.4), und so wird im Lutz-Verfahren wie im $\mathrm{CN}$-Verfahren die gleiche Abkürzung für den gleichen Parameter verwendet.

Abfluss tritt demnach erst dann auf, wenn der Niederschlag mehr als $20 \%$ der maximal möglichen Retention beträgt (in einigen Varianten des Verfahrens wird anstelle von $20 \%$ auch $5 \%$ verwendet, z. B. [16]). Mit zunehmendem Niederschlag wird ein immer 
kleinerer Anteil der noch nicht aufgefüllten Retention ausgeschöpft, sodass die Maximalretention $\mathrm{S}$ dann im Unendlichen erreicht wird.

Für verschiedene Böden und Flächennutzungen liegen tabellierte Werte vor (- Tab.4.1), die weltweit verwendet werden. Demnach steigt der $\mathrm{CN}$-Wert mit zunehmender Abflussneigung der Böden von der hydrologischen Bodengruppe A bis zur hydrologischen Bodengruppe D (zur Bestimmung der Bodengruppe s. Anhang 8.6) und bei den Nutzungen von „Kleegras über Wald, Wiese, “ Weide, Getreide, Reihenkulturen, Brachephasen zu Feldwegen und versiegelten Flächen hin an. Zur Ermittlung der Abflusshöhe eines Einzugsgebietes müssen die Flächennutzungen mit den örtlichen hydrologischen Bodengruppen verschnitten werden. Für die resultierenden homogenen Teilflächen sind die CN-Werte und deren Abfluss zu ermitteln [6]. Eine gewichtete Mittelung von $\mathrm{CN}$-Werten würde dagegen aufgrund des nicht-linearen Zusammenhangs zwischen $\mathrm{S}$ und $\mathrm{CN}$ vor allem bei moderaten Regen $<50 \mathrm{~mm}$ zu Fehlern im Abflussbeiwert von bis zu $50 \%$ führen [7].

- Tab. 4.1 suggeriert, dass der CN-Wert einer Landnutzung im Wesentlichen konstant ist bzw. auf landwirtschaftlichen Flächen zwischen zwei Werten variiert (einer für die Brachezeiten, bei wenig Bodenbedeckung und damit hoher Abflussneigung und einer für weitgehend voll entwickelte Bestände und damit geringer Abflussneigung). Dies ist stark vereinfachend und lässt die jahreszeitliche Dynamik vieler Kulturen außer Acht. Ein großer Teil des Jahresgangs in der Abflussneigung entsteht auf Ackerflächen durch den regelmäßigen Wechsel zwischen den Kulturen und den dazwischenliegenden Brachezeiten. Die Brache macht häufig ein Drittel, in ungünstigen Fällen sogar zwei Drittel des Jahres aus. Ein besonders ungünstiger Fall ist gegeben, wenn zwischen der Getreideernte im Juli und einem darauffolgenden Mais, bei dem wesentliches Wachstum erst im Mai auftritt, eine zehn Monate dauernde Brachephase liegt. Selbst bei Dauerkulturen können lange Brachephasen auftreten. Extremfall wäre hier der Spargel, bei dem die Ernte wesentliches Wachstum erst im Juli zulässt. Ein weiterer Einfluss, der einen Jahresgang der Abflussneigung bewirkt, ist der variierende Porenfüllungsgrad des Bodenwasserspeichers. Die Werte in - Tab.4.1 gelten daher nur für eine mittlere Bodenfeuchte (in der englischsprachigen Literatur wird dieser Zustand häufig mit „antecedent moisture condition II“ bezeichnet und der zugehörige $\mathrm{CN}$-Wert mit $\mathrm{CN}_{\mathrm{II}}$ symbolisiert).

Zusätzlich bestimmen zwei weitere Faktoren den Jahresgang der Abflussneigung einer Kultur: Erstens sinkt die Verschlämmungsneigung, je besser bedeckt ein Boden ist. Daher nimmt der $\mathrm{CN}$-Wert im Laufe der Vegetationsentwicklung ab. Zweitens kann ein Boden umso mehr Wasser aufnehmen, je stärker ausgetrocknet er ist. Da sowohl die Verschlämmung als auch die Entleerung des Bodenspeichers an einen wüchsigen Pflanzenbestand gekoppelt sind, wird der Jahresgang meist über eine Anpassung anhand des Bodenwasservorrats erreicht (-Abb. 4.1), der aber beide Einflüsse zusammenfasst. Weicht die Bodenfeuchte stark von mittleren Bedingungen ab $\left(\mathrm{CN}_{\mathrm{II}}\right)$, sind daher die Werte in - Tab. 4.1 mithilfe der folgenden Gleichung [19] anzupassen:

$$
C N=\frac{C N_{\mathrm{II}} \cdot 3,0646 \cdot e^{0,0235 \cdot M}}{10+C N_{\mathrm{II}} \cdot\left(0,030646 \cdot e^{0,0235 \cdot M}-0,1\right)}
$$

Der Parameter $M$ steht dabei für den prozentualen Porenfüllungsgrad des Bodens mit $\mathrm{M}=0$ für einen völlig trockenen Boden und $M=100$ für einen völlig gesättigten Boden. Beide Fälle kommen in der Natur praktisch nicht vor. Im Normalfall können Böden nur zwischen dem permanenten Welkepunkt (M kann dann mit 15 angenommen werden) und der Feldkapazität ( $\mathrm{M}$ ist dann etwa 85) variieren.

Eine Austrocknung unterhalb der Bodenoberfläche ist nur möglich, wenn ein wüchsiger Pflanzenbestand vorhanden ist, 
- Tab. 4.1 CN-Werte (Curve Number) bei mittlerer Entleerung des Bodenwasserspeichers $\left(\mathrm{CN}_{\|}\right)$für verschiedene Bodennutzungen und hydrologische Bodengruppen (nach [17], verändert). Die Tabelle wird nur für Flächennutzungen mit geringem Jahresgang empfohlen (offene Wasserflächen, Wald, Grünland, Siedlungsgebiete unterschiedlicher Dichte), während für Ackerkulturen die Gleichung in • Abb. 4.3 verwendet werden sollte. Auch bei Flächennutzungen mit geringem Jahresgang muss die hohe Bodenfeuchte im Winter berücksichtigt werden. Hinweise zur hydrologischen Bodengruppe können \ Anhang 8.6 entnommen werden

\begin{tabular}{|c|c|c|c|c|c|}
\hline \multirow[t]{2}{*}{ Landnutzung } & \multirow{2}{*}{$\begin{array}{l}\text { Abfluss- } \\
\text { neigung }\end{array}$} & \multicolumn{4}{|c|}{ Hydrologische Bodengruppe } \\
\hline & & A & B & $\mathrm{C}$ & D \\
\hline Offene Wasserflächen & & 100 & 100 & 100 & 100 \\
\hline Unbewachsener Boden ${ }^{a}$ & & 77 & 86 & 91 & 94 \\
\hline \multirow[t]{2}{*}{ Reihenfrüchte $^{b}$} & Hoch & 72 & 81 & 88 & 91 \\
\hline & Niedrig & 67 & 78 & 85 & 89 \\
\hline \multirow[t]{2}{*}{ Getreide $^{c}$} & Hoch & 65 & 76 & 84 & 88 \\
\hline & Niedrig & 63 & 75 & 83 & 87 \\
\hline \multirow[t]{2}{*}{ Kleegras/Luzerne ${ }^{d}$} & Hoch & 25 & 47 & 64 & 72 \\
\hline & Niedrig & 24 & 43 & 61 & 70 \\
\hline Weide & & 39 & 61 & 74 & 80 \\
\hline Wiese & & 30 & 58 & 71 & 78 \\
\hline \multirow[t]{3}{*}{ Wald } & Hoche & 45 & 66 & 77 & 83 \\
\hline & Mittel $^{f}$ & 36 & 60 & 73 & 79 \\
\hline & Niedrigg & 25 & 55 & 70 & 77 \\
\hline Wein (terrassiert) & & 64 & 73 & 79 & 82 \\
\hline Dörfl. Siedlung, Außensiedlung & & 59 & 74 & 82 & 86 \\
\hline Städtische Siedlung & & 61 & 75 & 83 & 87 \\
\hline Sport-/Golfplätze & & 39 & 61 & 74 & 80 \\
\hline Industrie/Gewerbegebiete/Straßen & & 89 & 92 & 94 & 95 \\
\hline Wege, befestigt & & 74 & 84 & 90 & 92 \\
\hline Wege, wassergebunden & & 72 & 82 & 87 & 89 \\
\hline Abbauland ${ }^{h}$ & & 77 & 86 & 91 & 94 \\
\hline
\end{tabular}

aZum Beispiel gepflügte Flächen oder Saatbett, bevor mindestens $10 \%$ Bedeckung erreicht ist

bMais, Zuckerrüben, Kartoffeln, Sonnenblumen und Ackerbohnen; Hopfen und Spargel werden in ihrer hydrologischen Wirkung ebenfalls wie Reihenfrüchte behandelt; hohe Abflussneigung entsteht insbesondere bei weitem Reihenabstand (Extremfall Spargel mit 1,2 m, aber auch bei konventionell angebautem Mais), spätem Wachstum (Extremfall wiederum Spargel, aber auch konventioneller Mais) und Bodenverdichtung durch schwere Erntemaschinen (besonders bei Silomais, Zuckerrüben, Kartoffeln) und Güllewagen. Weiter ist eine hohe Abflussneigung besonders in der Etablierungsphase (weniger als $50 \%$ Bodenbedeckung) gegeben

'Weizen, Gerste, Hafer, Roggen, Dinkel, Triticale, aber auch Raps und Buchweizen; hohe Abflussneigung liegt bei Getreide besonders in Jahren nach Reihenkulturen mit hohen Erntegewichten (besonders bei Silomais, Zuckerrüben, Kartoffeln) vor. Eine mittlere Abflussneigung ist im zweiten Getreidejahr zu erwarten. Weiter ist eine hohe Abflussneigung besonders in der Etablierungsphase (weniger als 50 \% Bodenbedeckung) gegeben. Besonders niedrige Abflussneigung tritt in Jahren nach mehrjährigem Ackerfutter (z. B. Kleegras) auf. Diesen Fall findet man besonders im organischen Landbau

${ }^{d}$ Die Werte weichen von den üblichen Tabellen ab. Sie folgen [18]. Die höheren Zahlen gelten im Etablierungsjahr, die niedrigeren Zahlen gelten im Folgejahr. Erfolgt die Etablierung nicht mit Saatbettbereitung, sondern mit Untersaat, sind für das erste Jahr Zwischenwerte zu verwenden

'Wälder und Forsten mit serpentinenartig ausgebauten, Lkw-befahrbaren Forststraßen

fWälder und Forsten mit traditionellen Forstwegen

gUrwaldähnliche, gestuft aufgebaute Wälder mit geringer (Forst-)Straßendichte

hSand-, Kies- Steinabbau, aber auch Bauplätze 


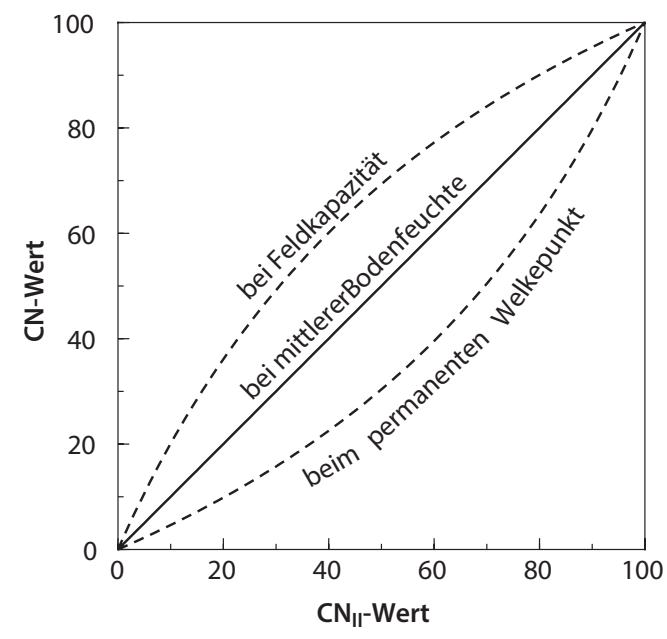

- Abb. 4.1 Anpassung des für mittlere Feuchteverhältnisse gültigen $\mathrm{CN}$-Wertes $\mathrm{CN}_{\|}$an abweichende Feuchteverhältnisse (Nach [19])

dessen Wurzeln aus dem Boden Wasser entnehmen, und wenn die klimatische Wasserbilanz (also die Differenz aus Niederschlag und potenzieller Evapotranspiration) über längere Zeit negativ ist. Eine negative klimatische Wasserbilanz tritt an einem mittleren Standort in Deutschland (mittlerer Jahresniederschlag $850 \mathrm{~mm} \mathrm{a}^{-1}$ ) im Mittel nur im Mai und im August auf, während in allen anderen Monaten die klimatische Wasserbilanz nahe null oder deutlich positiv (Oktober bis April) ist (• Abb.4.2). Daraus folgt, dass in der meisten Zeit des Jahres die CN-Werte einer bestimmten Flächennutzung nur zwischen der mittleren Linie in - Abb. 4.1 (50\% nutzbare Feldkapazität) und der oberen Linie (100\% Feldkapazität) liegen können, wenn nur die Bodenfeuchte einen Einfluss hätte. Da sich besonders der Niederschlag in einzelnen Jahren nicht ans langjährige Mittel hält, kann allerdings ein deutliches Wasserbilanzdefizit auch in anderen Monaten auftreten; und ebenso ist in allen Monaten möglich, dass der Bodenwasservorrat aufgefüllt ist, also sehr feuchte Bedingungen vorliegen. Daher tritt eine erhebliche Streuung um einen mittleren Jahresgang auf.
Da beide Einflüsse - Verringerung der Verschlämmungsneigung und Entleerung des Bodenwasserspeichers - an einen wüchsigen Pflanzenbestand gekoppelt sind, lassen sie sich im Normalfall kaum trennen. In Gebieten, in denen mehrere aride Monate mit negativer Wasserbilanz hintereinander auftreten, ist der Einfluss der Entleerung des Bodenwasserspeichers größer, und daher wird dort die Beziehung in - Abb.4.1 zur Erzeugung des Jahresgangs empfohlen. In Deutschland spielt dagegen der Jahresgang der Bodenfeuchte in den meisten Jahren nur eine untergeordnete Rolle (- Abb. 4.2). Vor allem auf ackerbaulich genutzten Flächen, die über $40 \%$ der Landesfläche ausmachen, wird der Jahresgang der CN-Werte dagegen sehr viel mehr durch den Jahresgang der Verschlämmbarkeit gesteuert. Da der mittlere Jahresgang der Bodenfeuchte wegen der nahezu durchgehend humiden Bedingungen die Unterschiede in der Verschlämmbarkeit nicht nachzeichnen kann, liegt es nahe, die CN-Werte direkt aus der Bedeckung zu schätzen, um zu einem Jahresgang zu kommen. In • Abb. 4.3 sind dazu 75 Beregnungsversuche bei unterschiedlichen

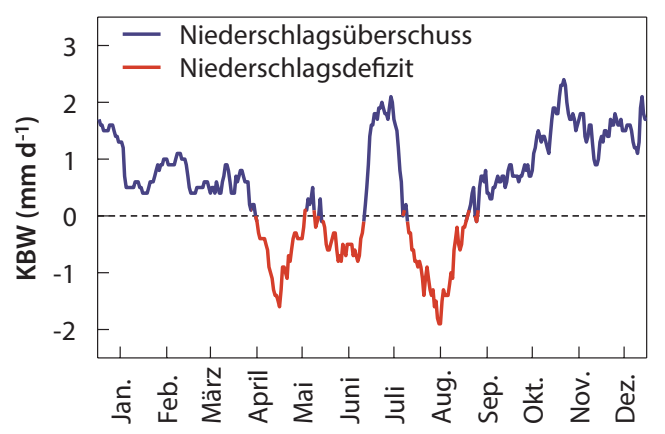

- Abb. 4.2 Langjährig mittlere klimatische Wasserbilanz (KWB) für einen Standort in Süddeutschland (mittlerer Jahresniederschlag $850 \mathrm{~mm} \mathrm{a}^{-1}$; mittlere potenzielle Verdunstung $630 \mathrm{~mm} \mathrm{a}^{-1}$ ); nur im Mai und im August werden etwa $40 \mathrm{~mm}$ aus der nutzbaren Feldkapazität entnommen. Für einen mittleren Boden mit $80 \mathrm{~mm}$ nutzbarer Feldkapazität ist dann der Zustand erreicht, für den die in - Tab. 4.1 aufgelisteten Werte gelten. Besonders für November bis April ist dagegen ein Zuschlag bei den $\mathrm{CN}$-Werten wegen hoher Bodenfeuchte vorzusehen 


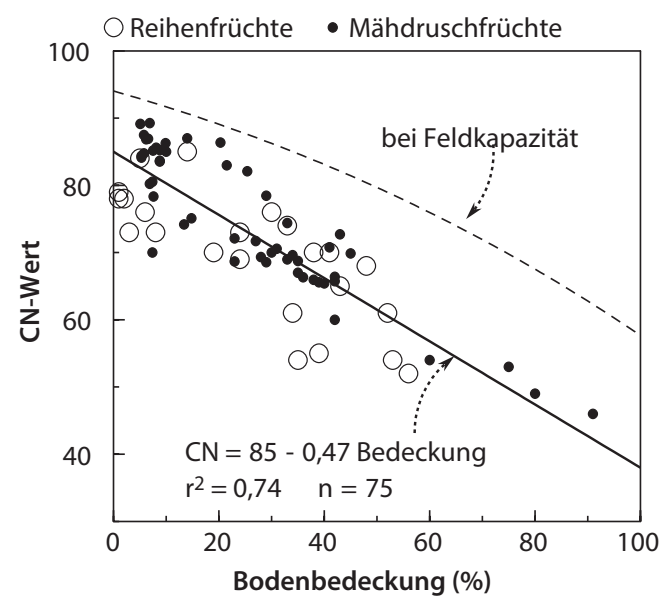

- Abb. 4.3 Einfluss der Bodenbedeckung auf die bei 75 Beregnungsversuchen mit etwa $65 \mathrm{~mm}$ Niederschlag auf unterschiedlichen Standorten und bei unterschiedlichen Kulturen gemessenen $\mathrm{CN}$ Werte (jeweils umgerechnet auf die hydrologische Bodengruppe C; Reihenfrüchte waren Zuckerrüben und Mais; Mähdruschfrüchte waren verschiedene Getreidearten und Raps). Die berechnete Veränderung der Beziehung bei hoher Bodenfeuchte (nahe der Feldkapazität in den Wintermonaten) ist gestrichelt eingezeichnet. Die Daten stammen von [20-23]

Kulturen (Getreide, Raps, Zuckerrüben, Mais) auf unterschiedlichen Standorten zusammengestellt (Daten aus [8, 20, 21]). Unabhängig von der Kultur folgen die gemessenen $\mathrm{CN}-$ Werte einer gemeinsamen Beziehung, die zur Schätzung des Jahresgangs verwendet werden kann:

$$
C N_{\text {II }}=85-0,47 \cdot \text { Bedeckung }
$$

Die Gleichung gilt für die hydrologische Bodengruppe C. Zur Übertragung in die Bodengruppen A, B und D dienen $>\mathrm{Gl} .4 .5$ bis $>$ Gl. 4.7. Die $>$ Gl. 4.4 ist einfacher $\mathrm{zu}$ handhaben als - Tab. 4.1, da nicht zwischen Zeiten (und Kulturen) mit hoher und niedriger Abflussneigung unterschieden werden muss. Ein weiter Reihenabstand oder ein frühes Stadium der Vegetationsentwicklung, die beide für eine hohe Abflussneigung verantwortlich sein können, werden durch die Bedeckung gleichermaßen und hinreichend gut erfasst. Eine Validierung dieser
Beziehung bei kleinen Regen, bei Regen mit Regenpausen, bei Regen auf verschlämmter Bodenoberfläche durch vorangegangene Starkregen und bei natürlichen Regen findet sich im $>$ Anhang 8.10.

Die in - Abb. 4.3 gezeigten Beregnungen wurden nur während der Vegetationsperiode durchgeführt. Die Messwerte gelten daher nur für Bedingungen, in denen der Bodenwasserspeicher teilweise entleert ist. Für die Wintermonate (November bis März; je nach Vegetationsperioden der Kulturen etwas unterschiedlich) ist eine Anpassung nach - Abb.4.1 bzw. Gl.4.3 notwendig, um die dann überdurchschnittliche Bodenfeuchte zu berücksichtigen. Zur einfacheren Handhabung sind in - Tab.4.2 die monatlichen $\mathrm{CN}$-Werte wichtiger Landnutzungen zusammengestellt, die die Einflüsse von Bracheperioden, variierender Bedeckung und Bodenfeuchte auf den Jahresgang berücksichtigen. Sie wird als zentrale Tabelle zur Anwendung des CN-Verfahrens in Deutschland empfohlen.

Mittelt man die monatlichen $\mathrm{CN}$-Werte entsprechend des Anteils der verschiedenen Flächennutzungen (was, wie oben dargestellt, nicht ganz korrekt ist) und vergleicht dies mit CN-Werten, die aus gemessenen Ereignisabflüssen ermittelt wurden, so zeigt sich eine bemerkenswert gute Übereinstimmung des Jahresgangs (• Abb. 4.4).

In der Literatur findet man nur wenige Fälle, in denen die CN-Werte nach der Bedeckung differenziert werden. Dagegen wird die Feuchtekorrektur häufig angewendet, obwohl sie in humiden Gebieten eigentlich nur in der Winterperiode oder unter Bedingungen, bei denen die Bodenfeuchte auf Werte nahe der Feldkapazität ansteigt, notwendig wäre. Die häufige Verwendung der Feuchtekorrektur liegt zum einen daran, dass zur Landnutzung oft keine hinreichenden Daten vorliegen und sie daher nur sehr pauschal berücksichtigt wird. Dagegen kann die Bodenfeuchte, wenn auch stark vereinfacht, allein durch meteorologische Daten abgeschätzt werden, selbst 
- Tab. 4.2 Monatliche CN-Werte unterschiedlicher Ackerkulturen unter deutschen Anbaubedingungen und von Grünland, Wald, Siedlungs- und Verkehrsfächen für die hydrologische Bodengruppe C. Die Tabelle berücksichtigt den Jahresgang in der Vegetationsentwicklung und gegebenenfalls Brachephasen. Für die Monate Mai bis September (je nach Vegetationsverlauf für die verschiedenen Kulturen etwas unterschiedlich) wurden mittlere Feuchteverhältnisse angenommen und $\triangleright \mathrm{Gl}$. 4.4 verwendet. Für die Monate November bis März wurde angenommen, dass die Bodenfeuchte nahe der nutzbaren Feldkapazität liegt, und die CN-Werte wurden nach • Abb. 4.1 korrigiert. Für die dazwischenliegenden Monate April und Oktober wurden Zwischenwerte verwendet. Der Jahresgang der Bodenbedeckung bei Ackerkulturen wurde aus [24] bzw. [25] entnommen. Aus Gründen der Übersichtlichkeit wurden mehrere Kulturen (z. B. verschiedene Wintergetreidearten) und Flächennutzungen (z. B. verschiedene Formen des Grünlandes, der Wälder, der Siedlungs- und Verkehrsflächen) zusammengefasst und müssten gegebenenfalls differenziert werden.

\begin{tabular}{|c|c|c|c|c|c|c|c|c|c|c|c|c|}
\hline & J & $\mathrm{F}$ & M & A & M & J & J & A & $\mathrm{S}$ & $\mathrm{O}$ & $\mathrm{N}$ & $\mathrm{D}$ \\
\hline $\begin{array}{l}\text { Sommer- } \\
\text { getreide }\end{array}$ & 95 & 95 & 95 & 80 & 46 & 44 & 44 & 44 & 87 & 91 & 95 & 95 \\
\hline Wintergetreide ${ }^{b}$ & 95 & 88 & 66 & 54 & 44 & 44 & 70 & 80 & 87 & 91 & 95 & 95 \\
\hline Mais $^{c}$ & 94 & 94 & 94 & 90 & 88 & 73 & 50 & 43 & 62 & 85 & 90 & 94 \\
\hline Zuckerrüben ${ }^{c}$ & 95 & 94 & 94 & 88 & 86 & 62 & 50 & 43 & 41 & 70 & 91 & 95 \\
\hline Kartoffeln & 95 & 94 & 94 & 88 & 86 & 62 & 50 & 45 & 43 & 70 & 91 & 95 \\
\hline Kleegras $^{d}$ & 82 & 82 & 73 & 62 & 62 & 62 & 62 & 62 & 62 & 62 & 62 & 71 \\
\hline Grünland & 87 & 87 & 87 & 79 & 72 & 72 & 72 & 72 & 72 & 79 & 87 & 87 \\
\hline Wald & 88 & 88 & 88 & 80 & 73 & 73 & 73 & 73 & 73 & 80 & 88 & 88 \\
\hline Siedlung & 93 & 93 & 93 & 87 & 82 & 82 & 82 & 82 & 82 & 87 & 93 & 93 \\
\hline Verkehr & 98 & 98 & 98 & 96 & 94 & 94 & 94 & 94 & 94 & 96 & 98 & 98 \\
\hline \multicolumn{13}{|c|}{$\begin{array}{l}\text { aVor allem Sommerweizen, Sommergerste und Hafer } \\
\text { bVor allem Winterweizen, Wintergerste, Winterroggen, Triticale, aber auch Raps } \\
\text { cKonventioneller Anbau; bei Mulchsaat und besonders bei Mulchdirektsaat deutliche Abschläge (s. } \\
\text { - Abb. 4.3) }\end{array}$} \\
\hline
\end{tabular}

wenn keine genauen Informationen über die Porengrößenzusammensetzung des Bodens und den prozentualen Porenfüllungsgrad zur Verfügung stehen. Dies erscheint daher als die einfachere Option, als Landnutzungsdaten zeitdifferenziert zu erheben. Noch wichtiger für die weite Verbreitung der Feuchtekorrektur ist aber ein zweiter Grund. Die Feuchtekorrektur erlaubt scheinbar relativ einfach und plausibel, einen Datenfehler zu beseitigen, der oft vorliegt. Dies soll an einem kleinen Beispiel illustriert werden:

Das CN-Modell ist ein Ereignismodell und erfordert daher Ereignisniederschläge. Meteorologische Quellen weisen aber häufig nur Tagesniederschläge aus, die $\mathrm{zu}$ falschen Aussagen führen. Angenommen ein 60-mmNiederschlag fällt gleichmäßig über zwei Tage verteilt (je $30 \mathrm{~mm}$ ). Wenn der $\mathrm{CN}$ Wert 80 beträgt, dann ergibt sich für das 60-mm-Ereignis ein Abfluss von 20,2 mm. Rechnet man dagegen mit zwei Tagesniederschlägen von $30 \mathrm{~mm}$, so ergibt sich an beiden Tagen ein Abfluss von jeweils 3,7 mm, in der Summe also nur 7,4 mm. Die Differenz kommt daher, weil bei ereignisweiser Berechnung am ersten Tag zwar auch nur $3,7 \mathrm{~mm}$ abfließen, am zweiten Tag aber $(20,2-3,7) \quad 16,5 \mathrm{~mm}$. Damit ist die Berechnung mit Tagesniederschlägen in so einem Fall grob falsch. Hier 


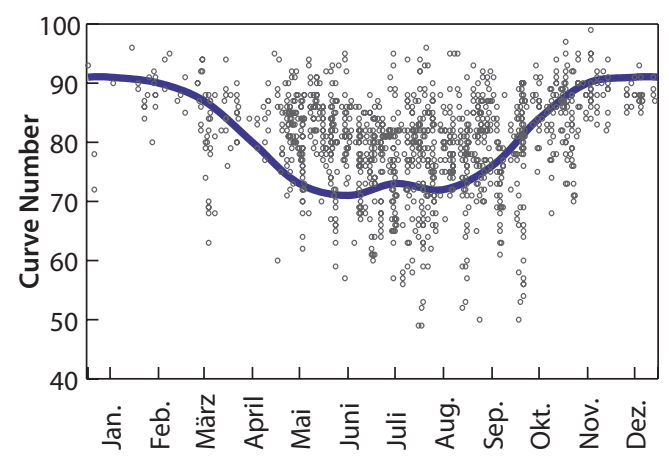

- Abb. 4.4 Mittlerer Jahresgang der CN-Werte, wenn man die Landnutzungsverteilung von Bayern zugrunde legt (Linie). Zum Vergleich sind 1174 CN-Werte eingezeichnet (Symbole), die aus Ereignisabflüssen von 22 Einzugsgebieten in Bayern mit Flächengrößen von 12 bis $170 \mathrm{~km}^{2}$ berechnet wurden (Daten aus [26])

kommt nun die Feuchtekorrektur ins Spiel. Da am ersten Tag $30 \mathrm{~mm}$ fallen, muss die Bodenfeuchte stark ansteigen. Wird beispielsweise angenommen, dass der Porenfüllungsgrad von $50 \%$ auf $80 \%$ steigt, ist der CN-Wert am zweiten Tag nach $>$ Gl. 4.3 nicht mehr 80 sondern 89. Der Abfluss des zweiten Tages ist daher nicht mehr 3,7 mm, wie am ersten Tag, sondern am zweiten Tag wird dann ein Abfluss von 10,1 mm erwartet, obwohl an dem Tag auch nur $30 \mathrm{~mm}$ Niederschlag fallen. Die Diskrepanz zur korrekten Berechnung ist daher wesentlich vermindert, auch wenn immer noch eine Diskrepanz bleibt. Vergleicht man nun die Berechnung mit Feuchtekorrektur mit gemessenen Abflüssen in Gewässern, zeigt sich eine wesentlich bessere Übereinstimmung als ohne Feuchtekorrektur. Daraus wird häufig gefolgert, dass eine Feuchtekorrektur unbedingt notwendig ist. Dabei hat sie nur den Fehler, der durch die Verwendung von Tagesniederschlägen entstand, etwas vermindert. Ohne diesen Fehler wäre sie nicht notwendig gewesen. Oder umgekehrt: Liegen nur Tagesniederschläge vor, sollten Regentage nach Regentage als ein zusammenhängendes Ereignis betrachtet werden. Für zwei aufeinander- folgende Regentage ergäbe sich daher folgender Rechenweg: Der Abfluss des ersten Regentages ergibt sich durch die übliche Berechnung. Der Abfluss des zweiten Regentages wird dagegen berechnet, indem man den Regen beider Tage addiert, den Abfluss für diese Regensumme berechnet und von diesem Abfluss den Abfluss des ersten Regentages abzieht. Die Eignung dieses Verfahrens wird im - Abb 8.25 anhand experimenteller Daten gezeigt. Es gilt auch für feiner aufgelöste Daten mit kurzen Regenpausen. Letztere dürfen beim $\mathrm{CN}$-Verfahren nicht als Kriterium für die Trennung von Ereignissen verwendet werden.

- Tab.4.2 differenziert scheinbar stark bei Ackerkulturen und wenig bei anderen Landnutzungen. Dies ist aber nur scheinbar so, da die Jahresgänge der verschiedenen Ackerkulturen sich sehr viel stärker unterscheiden als beispielsweise die Jahresgänge der verschiedenen Grünland- oder Waldtypen. Für Grünland und Wald wurden nur mittlere Verhältnisse berücksichtigt, aber zusammen mit - Tab. 4.1 kann auch leicht ein Jahresgang für andere Verhältnisse erzeugt werden. Zur weiteren Differenzierung von Wäldern und alpinen Boden/Vegetationseinheiten sei auf [27] verwiesen, die allerdings keine $\mathrm{CN}$-Werte ausweisen und vor allem nach dem Boden und damit indirekt nach der Hydrologischen Bodengruppe differenzieren.

Für Ackerkulturen wäre dagegen viel eher eine weitere Differenzierung notwendig, da sich beispielsweise die Wintergetreidearten Wintergerste und Winterweizen besonders von Spätherbst bis Frühjahr stark in ihrem Wachstum unterscheiden. Auch wird nicht zwischen den verschiedenen Anbauformen unterschieden. Darauf wird weiter unten noch etwas näher eingegangen. In einzelnen Fällen kann es daher notwendig sein, - Tab.4.2 zu erweitern. In den meisten Fällen, in denen viele Nutzungen und Nutzungsvarianten in einem Einzugsgebiet auftreten und die genauen Bedingungen häufig nicht bekannt sind, dürfte - Tab. 4.2 ausreichend differenziert sein. 
In - Tab.4.2 fällt weiter auf, dass besonders in den Sommermonaten die CN-Werte von Wald z. T. über den von Ackerkulturen liegen, was zunächst verwundert. Auch wenn CN-Werte für Wald unter deutschen Klimabedingungen einer Überprüfung bedürfen, dürfte diese Diskrepanz vor allem auf zwei Fehleinschätzungen beruhen. Erstens stocken viele Wälder auf relativ steinigen, grobkörnigen Substraten, die eher den hydrologischen Bodengruppen A oder B angehören, aber nicht der Bodengruppe C, die in - Tab. 4.2 ausgewiesen ist. Wie aus - Tab. 4.1 ersichtlich ist, nimmt der $\mathrm{CN}$-Wert bei diesen Bodengruppen deutlich $\mathrm{ab}$, was auch mit der Einstufung des Oberflächenabflussbeiwertes nach [27] übereinstimmt, der Wälder im Wesentlichen nach den Böden differenziert. Niedrige Abflüsse unter Wald sind daher vor allem auf Bodeneigenschaften zurückzuführen, die in - Tab. 4.2 ausgeklammert sind, aber mit $>$ Gl. 4.5, 4.6 und 4.7 einfach berücksichtigt werden können. - Abb.8.24 im Anhang zeigt den damit berechneten Jahresgang der CN-Werte unter Wald für die hydrologischen Bodengruppen A, B und C. Nicht in diesen Gleichungen berücksichtigt ist, dass auf steinigen, grobkörnigen Substraten die Feuchtefluktuation wesentlich stärker ist als auf den überwiegend lehmigen, von Ackerbau dominierten Böden der hydrologischen Bodengruppe $\mathrm{C}$, die ein deutlich höheres Wasserspeichervermögen aufweisen. Dies zeigen auch Messungen und Modellierungen kleiner, forstlich genutzter Bacheinzugsgebiete im Hunsrück, die eine enorme Variabilität der Gebietsabflüsse bis hin zu vollständigem Trockenfallen aufzeigten, wobei jedoch die Menge an Oberflächenabfluss gleichzeitig sehr hoch war [28]. Eine zusätzliche Berücksichtigung der Bodenfeuchtefluktuation während der Vegetationsperiode nach $\triangleright$ Gl. 4.3 kann also besonders bei Wäldern angebracht sein.

Zweitens beruht diese Diskrepanz z.T. darauf, dass bei Wäldern der Abfluss stark verzögert und damit mit geringem Scheitel fließt. Dies wird aber bei der Abflusskonzentration berücksichtigt und bedeutet nicht, dass die Abflussmenge gering ist. Auch dies zeigen die detaillierten Untersuchungen von [28]: Eine tatsächliche Versickerung und Grundwasserneubildung unter Wald trat fast nur in Kamm- und Oberhanglagen auf, während auf Mittelhängen langsam fließender Zwischenabfluss dominierte. Auf den feuchten Unterhängen dominierte Sättigungsflächenabfluss. Die Unterhänge waren daher hauptverantwortlich für den (schnellen) Hochwasserabfluss. In der Summe aus langsam fließenden Zwischenabfluss und schnellem Sättigungsflächenabfluss verließen pro Jahr bis zu $53 \%$ der eingehenden Niederschläge den Modellhang von [28] als Abfluss, was ein hohes Abflusspotenzial auch bei Wäldern belegt. In $>$ Anhang $8.10 \mathrm{im}$ Anhang findet sich eine genauere Analyse der Daten aus [28] und der Vergleich mit den in - Tab. 4.2 empfohlenen Werten.

- Gl. 4.3 und - Tab. 4.2 gelten für mittlere hydrologische Verhältnisse (hydrologische Bodengruppe C). Für abweichende hydrologische Bodengruppen müssen die Werte angepasst werden. Dies ist mit folgenden Regressionen möglich, die sich aus den Werten der - Tab. 4.1 ergeben. Die CN-Werte für die hydrologische Bodengruppe $\mathrm{A}\left(\mathrm{CN}_{\mathrm{A}}\right)$ berechnet sich aus den $\mathrm{CN}$-Werten der hydrologischen Bodengruppe $\mathrm{C}\left(\mathrm{CN}_{\mathrm{C}}\right)$ :

$$
C N_{A}=2,38 \cdot C N_{C}-136,6
$$

Für die $\mathrm{CN}$-Werte der hydrologische Bodengruppe $\mathrm{B}\left(\mathrm{CN}_{\mathrm{B}}\right)$ gilt:

$$
C N_{B}=1,46 \cdot C N_{C}-46,4
$$

Und für die $\mathrm{CN}$-Werte der hydrologische Bodengruppe $\mathrm{D}\left(\mathrm{CN}_{\mathrm{D}}\right)$ gilt:

$$
C N_{D}=0,78 \cdot C N_{C}+22,5
$$

Welchen Einfluss der Jahresgang der CN-Werte auf die Menge an Oberflächenabfluss hat, lässt sich aus den CN-Werten nicht direkt ablesen. Dazu müssen $>$ Gl.4.1 und 4.2 auf die CN-Werte der verschiedenen 
Kulturen und Flächennutzungen angewendet werden. Zur Illustration wurde in allen Monaten ein einheitlicher Bemessungsniederschlag von $40 \mathrm{~mm}$ zugrunde gelegt, um den Vergleich der Monate zu erleichtern. Dabei zeigt sich, dass sich durch den Jahresgang in der Vegetationsentwicklung und der Entleerung des Bodenspeichers auch ein sehr ausgeprägter Jahresgang in der Abflussbildung ergibt (- Abb. 4.5). Während in den Wintermonaten etwa $50 \%$ eines 40-mm-Regens abfließen, sind es in den Sommermonaten nur etwa $15 \%$ (angenommen wurde einheitlich die hydrologische Bodengruppe $\mathrm{C}$ und die Landnutzungsverteilung in Deutschland).

Noch deutlicher wird der ausgeprägte Jahresgang, wenn man sich den Beitrag der verschiedenen Flächennutzungen zum Gesamtabfluss anschaut. Die Siedlungsund Verkehrsflächen und auch die offenen Gewässer tragen weit mehr, als ihrem Flächenanteil entspricht, zum Gesamtabfluss bei. Dies ist besonders ausgeprägt in den Sommermonaten, während der Hauptwachstumsphase der Ackerkulturen. Wald und Grünland tragen weniger bei, als ihrem Flächenanteil entspricht, aber ihr Anteil am Gesamtabfluss ist wegen ihres großen Flächenanteils nicht unerheblich. Insbesondere ist der Beitrag des Waldes durch die starke Zerschneidung und den Eingriff in den Bodenwasserhaushalt durch den Forststraßenbau nicht unbedeutsam. Die ackerbaulichen Flächennutzungen Sommergetreide, Wintergetreide und Mais einschließlich anderer Hackfrüchte tragen im Mittel genauso viel zum Gesamtabfluss bei, wie ihrem Flächenanteil entspricht. Allerdings sind die jahreszeitlichen Unterschiede enorm. Wintergetreide einschließlich Raps dominieren den Abfluss von Ackerflächen von Juli, wenn die Ernte beginnt, bis zum Februar. Mit Einsetzen der Hauptwachstumsphase im März wird der Anteil des Wintergetreides verschwindend gering. Ab dann bis in den Frühsommer dominiert der Abfluss von Flächen
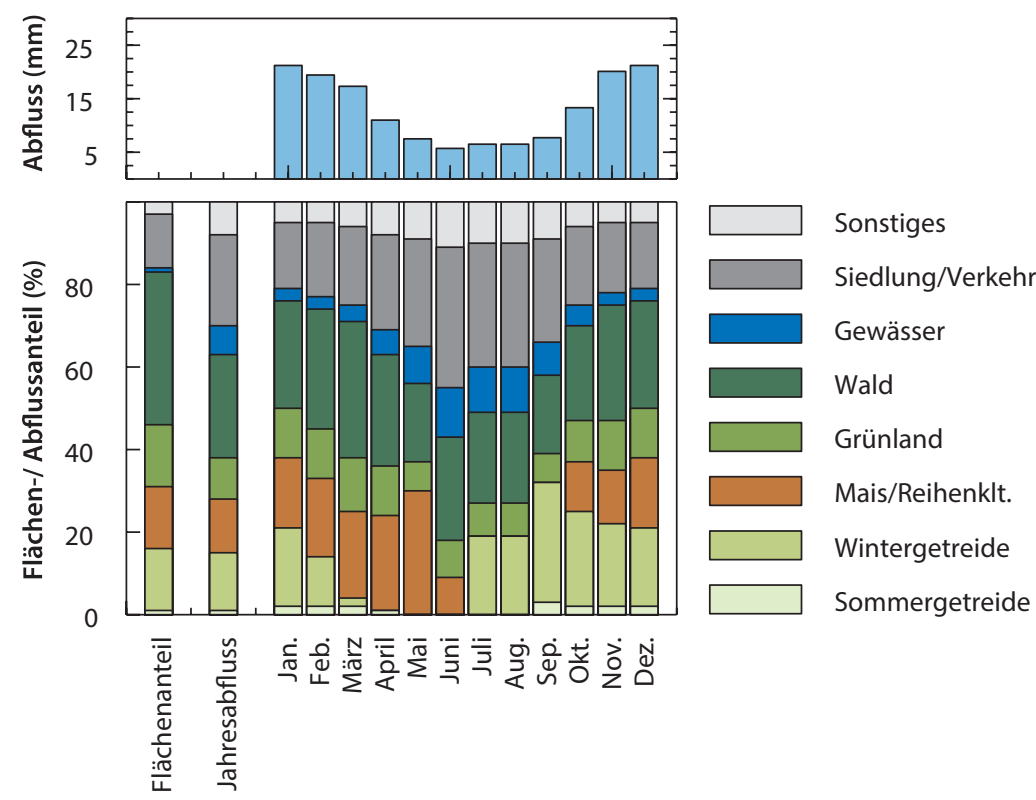

- Abb. 4.5 Mittlerer erwarteter Abfluss (oben) bei einem Regenereignis mit 40 mm und der Landnutzungsverteilung in Deutschland auf einem Standort der hydrologischen Bodengruppe C. Die untere Tafel zeigt den Anteil der verschiedenen Kulturen und Landnutzungen an der Gesamtfläche (zu Gruppen zusammengefasst, um die Lesbarkeit zu erhöhen) und ihren Beitrag zum oben dargestellten Gesamtabfluss 
mit Mais und anderen Hackfrüchten. Löst man feiner auf, z. B. zwischen verschiedenen Wintergetreidearten und zwischen verschiedenen Hackfrüchten, treten wegen des versetzten Wachstums weitere Unterschiede zutage.

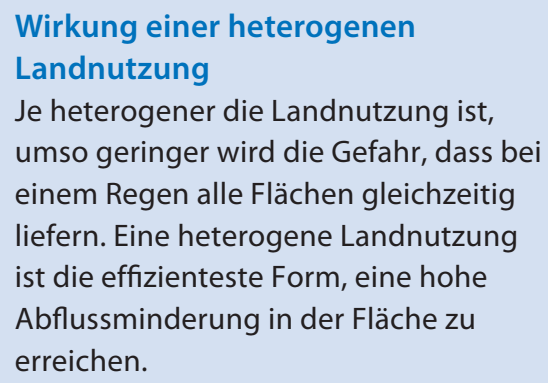

Bei kleineren Regen als dem angenommenen Bemessungsniederschlag von $40 \mathrm{~mm}$ werden die Unterschiede noch größer, da dann manche Landnutzungen zu manchen Jahreszeiten überhaupt keinen Abfluss liefern, sondern bei ihnen der Regen vollständig infiltriert.

Dies Lücke des Maises und anderer Hackfrüchte im Winter, Frühjahr und Frühsommer wird idealerweise durch den Anbau einer abfrierenden Zwischenfrucht direkt nach der Getreideernte geschlossen (z. B. Senf, Ölrettich oder Phazelia). Die Zwischenfrucht kann ohne wendende Bodenbearbeitung gesät werden, sodass das Getreidestroh den Boden bedeckt, bis diese Aufgabe die im Sommer rasch keimende Zwischenfrucht übernimmt. In die abgefrorene Zwischenfruchtdecke wird dann die folgende Hauptfrucht, also z. B. Mais, am besten in Mulchdirektsaat angebaut, um keine Lücke im Frühsommer entstehen zu lassen (Direktsaat bedeutet, dass gesät wird, ohne die Mulchdecke durch eine Bearbeitung $\mathrm{zu}$ beinträchtigen). Mulchsaat mit einer Bodenbearbeitung bei der Aussaat der Hauptfrucht mindert die Abflussneigung im Frühsommer nicht mehr, weil durch die Bearbeitung nach der Aussaat nur wenig
Mulchbedeckung übrigbleibt. In beiden Fällen - Mulchsaat oder Mulchdirektsaat - sinkt durch die im Herbst angebauten und bis zum Winter wachsenden Zwischenfrüchte aber die Abflussneigung in den Wintermonaten deutlich, wenn die Abflussneigung generell am höchsten ist (- Abb.4.6). Dieser Zusammenhang ist auch durch Messdaten belegt [22]. Ähnlich günstige Werte wurden für nicht

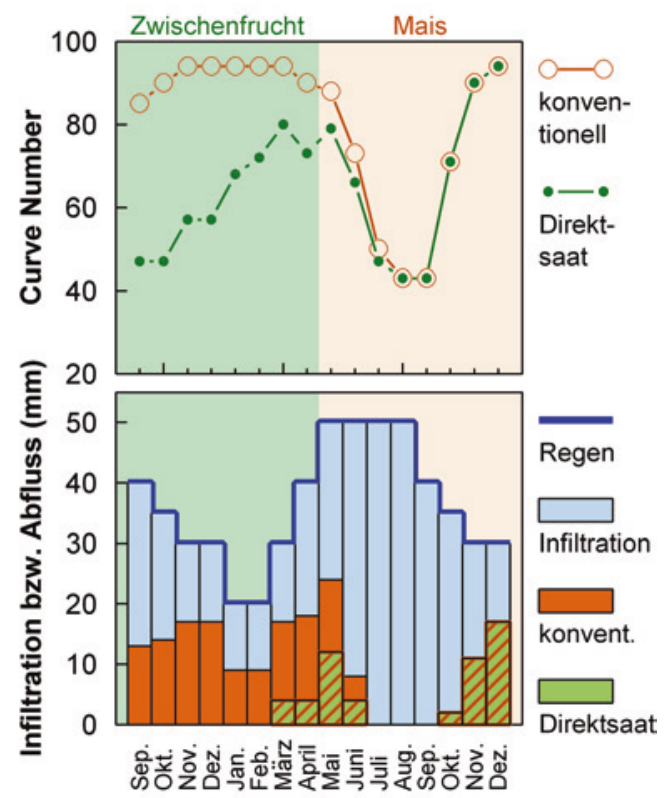

- Abb. 4.6 oben: Jahresgang der CN-Werte von konventionell angebautem Mais und von Mais in Mulchdirektsaat, beginnend im September des Vorjahres (nach einer Getreidevorfrucht). Wird statt Mulchdirektsaat die Saat von Mais mit einer Bodenbearbeitung kombiniert (Mulchsaat), sind ab einschließlich Mai die Werte für konventionellen Mais zu verwenden, während davor die Werte gleich sind wie bei Mulchdirektsaat. Die Werte gelten für die hydrologische Bodengruppe C. Unten: Zur Illustration der Wirkung wurde der Abfluss berechnet. Dabei wurde ein Regen von $50 \mathrm{~mm}$ im Sommer, ein Regen von $20 \mathrm{~mm}$ in den Wintermonaten und Zwischenwerte in den übrigen Monaten angenommen. Grün ist der zu erwartende Abfluss bei Mulchdirektsaat-Mais, braun ist der bei konventionell angebautem Mais zusätzlich zu erwartende Abfluss und blau ist der infiltrierende Anteil des Regens. Die Summe der drei Balken entspricht daher der Regenhöhe 
bearbeiteten („no-till“) Mais, gemessen, der aber in Deutschland nicht verbreitet ist. Langzeitversuche ergaben dafür mittlere $\mathrm{CN}$-Werte von 66, wohingegen die mittleren $\mathrm{CN}$-Werte bei konventioneller (wendender) Bearbeitung bei rund 90 lagen [18].

Der Einfluss der Hangneigung auf die Abflussbildung wird in der Literatur kontrovers diskutiert. Physikalisch betrachtet lässt die Hangneigung zunächst keinen eindeutigen Einfluss auf die Infiltration erwarten, im Gegensatz zur Fließgeschwindigkeit von Oberflächenabfluss, die stark von der Hangneigung abhängt (s. GMS-Gl. 5.5). Trotzdem finden sich Einflüsse der Hangneigung auf den Abfluss; Messungen haben sowohl die Zunahme als auch die Abnahme der Infiltrationsrate mit zunehmender Hangneigung gezeigt [29]. Eine Zunahme der Infiltration und damit die Abnahme des Oberflächenabflusses auf wenig bedeckten, relativ glatten Oberflächen wird dadurch erklärt, dass mit zunehmender Hangneigung die Erosion durch die erhöhte Fließgeschwindigkeit zunimmt $[30,31]$. In Folge geht die Verschlämmung der Bodenoberfläche zurück, wodurch ihre Infiltrationsfähigkeit erhalten bleibt. Im Landschaftsmaßstab wirkt zusätzlich ein weiterer Prozess. Rauhigkeitselemente wie Feldraine oder Pflugfurchen sind in diesem Maßstab nicht mehr $\mathrm{zu}$ vernachlässigen. Es wird häufig davon ausgegangen, dass die Zwischenspeicherung und vermehrte Infiltration von Oberflächenabfluss hinter solchen Rauhigkeitselementen zunimmt, je geringer die Hangneigung ist. In dem Fall nimmt der Abfluss ab, der ein Einzugsgebiet verlässt. Auch wenn die experimentelle Basis für diesen Zusammenhang gering ist und nicht bekannt ist, wie viele und welcher Art solche Rauhigkeitselemente vorhanden sein müssen, wurden auf Einzugsgebietsebene (nicht auf Ebene eines einzelnen Feldes) unterschiedliche Gleichung zur Berücksichtigung der Hangneigung vorgeschlagen (z. B. in [6]). Da die Hangneigung in manchen dieser Gleichungen einen großen Einfluss auf den CN-Wert hat, die Skala, auf der die Hangneigung zu bestimmen ist, nicht immer eindeutig definiert ist, wird eine pauschale Anwendung dieser Korrekturgleichungen aber nicht empfohlen.

Bewusst und zusätzlich zum „Normalfall“, dem Anbau in Gefällerichtung, werden abflussspeichernde Rauhigkeitselemente geschaffen, wenn konturparallel angebaut wird (dies bedeutet, dass auf ein Vorgewende verzichtet werden muss, das in Gefällerichtung laufen würde; vgl. - Abb.6.6). Bei konturparalleler Bewirtschaftung sinken die $\mathrm{CN}$-Werte $\left(\mathrm{CN}_{\text {Kontur }}\right)$ gegenüber den oben dargestellten, für Bewirtschaftung mehr oder weniger in Gefällerichtung geltenden CN-Werten nach [5]:

$$
C N_{\text {Kontour }}=-0,2+0,97 \cdot C N
$$

Noch stärker sinken die CN-Werte bei konturparalleler Terrassierung des Geländes, weil dann auch die Neigung der Flächen geringer wird und die Terrassenkanten zusätzlich als Barrieren wirken (abgeleitet aus [5]):

$$
C N_{\text {Terrassiert }}=0,7+0,92 \cdot C N
$$

\subsection{Modellregen für den ländlichen Hochwasserschutz}

Zur Dimensionierung von Bauwerken wie Durchlässen, Rückhaltebecken, Kanalnetzen oder Entlastungsbauwerken werden in der wasserwirtschaftlichen Praxis Bemessungsniederschläge und Bemessungsabflüsse verwendet. Sie werden über die Wahrscheinlichkeit, mit der sie auftreten, bzw. über die Zeiträume, in denen sie einmal zu erwarten sind (z. B. jährlich oder alle 10, 50, 100, ... Jahre) definiert. Diese Überlegung lässt sich auch auf die ländliche Flur übertragen, um beispielsweise die Breite von begrünten Abflussmulden, die Wirkung von Gräben oder den Einfluss von Bewirtschaftungsmaßnahmen auf den Abfluss abzuschätzen oder um das erforderliche Volumen kleiner Rückhaltebecken zu ermitteln. 
Bemessungsabflüsse werden unter anderem mit statistischen Methoden, mit Übertragungs- und Schätzverfahren (Regionalisierung) oder durch NiederschlagAbfluss-Modellierung bestimmt [12, 32-34]. Zur Ableitung von Maßnahmen sind insbesondere Niederschlag-Abfluss-Modellierungen gut geeignet, da empirische oder statistische Verfahren Veränderungen in der Abflussbildung (z. B. Änderung der Landnutzung) und -konzentration (z. B. Erhöhung der Rauigkeit entlang der Entwässerungswege) in der Regel nicht abbilden können. Hinzu kommt, dass in kleinen Gebieten üblicherweise keine (quantitativen) Informationen über historische Niederschlag-Abfluss-Ereignisse vorliegen und statistische Verfahren dadurch vielfach nicht anwendbar sind.

Bei Niederschlag-Abfluss-Modellierungen wird - meist für synthetische Modell- und Bemessungsregen - zunächst die Höhe des abflusswirksamen Niederschlagsanteils (z. B. mit dem CN- oder dem Lutz-Verfahren) ermittelt. Aus ihm ergibt sich durch Multiplikation mit der Einzugsgebietsfläche $\left(\mathrm{A}_{\mathrm{EZG}}\right)$ das Volumen des abfließenden Niederschlags bzw. des Abflusses des Einzugsgebietes. Unter Berücksichtigung der Fließzeit ergibt sich die Scheitelhöhe einer Abflusswelle an einem definierten Punkt. Die Basis dieses Ansatzes ist daher immer ein definierter Modell- oder Bemessungsniederschlag. Bemessungsniederschläge lassen sich aus unterschiedlichen Datengrundlagen ableiten, wobei sich in der Praxis vor allem die durch Extremwertstatistik ermittelten, koordinierten Starkniederschlagshöhen (KOSTRA) des Deutschen Wetterdienstes (DWD) etabliert haben [35]. Letztere sind Regenereignisse mit definierten Eigenschaften wie Niederschlagshöhe (N) und -dauer (D). Zusätzlich verfügen sie über eine aus Messzeitreihen der Vergangenheit abgeleitete Wiederkehrwahrscheinlichkeit $\left(\mathrm{T}_{\mathrm{n}}\right)$ (auch als Jährlichkeit oder Annuität bezeichnet).

Die Wahl des Bemessungsniederschlags hat einen großen Einfluss auf das Ergebnis der Abflussmodellierung. Mit der Wahl wird das angestrebte Dimensionierungsziel bzw. der Schutzgrad berücksichtigt. Dies hängt von der Aufgabenstellung ab. Im folgenden Kapitel werden zunächst übliche, in der Wasserwirtschaft verbreitete Bemessungsziele beschrieben. Daraus werden Empfehlungen für den ländlichen Hochwasserschutz abgeleitet. Im Anschluss werden wesentliche Aspekte des KOSTRA-Datensatzes beschrieben, da dieser für viele praktische Fragestellungen geeignet ist. Weitere Aspekte zur Ableitung von Modell- und Bemessungsregen sind in $>$ Anhang 8.4 zusammengestellt. Diese umfassen die Berücksichtigung von Schnee und Methoden zur Ableitung von Ganglinien für Gebiets- und Bemessungsniederschläge aus Stations- oder Radardaten.

\subsubsection{Bemessungsziele in der Wasserwirtschaft und Ableitung von Bemessungszielen für die Flur}

Unter einem Bemessungsziel versteht man einen Regen oder einen Abfluss, der durch eine $\mathrm{zu}$ planende Maßnahme (eine Verrohrung, eine Brücke etc.) gerade noch beherrscht werden soll. Dabei orientiert man sich an ungünstigen Bedingungen, also einem selten zu erwartenden Abflussvolumen oder einem selten $\mathrm{zu}$ erwartenden Abflussscheitel. Wie selten, wird durch das Wiederkehrintervall ausgedrückt (z. B. der 30-jährliche Regen oder Abfluss). Dabei wird üblicherweise angenommen, dass ein 100-jährlicher Regen einen 100-jährlichen Abfluss erzeugt (analog bei anderen Wiederkehrzeiten), und weiter, dass extreme Regen der Vergangenheit geeignete Schätzgrößen für extreme Regen in der Zukunft sind (dies wird als Stationarität bezeichnet). Dadurch lassen sich mithilfe langer Messreihen und Verfahren der Extremwertstatistik Regen und Abflüsse mit statistisch definierten Eigenschaften (Jährlichkeit, Menge und Dauer) ermitteln. Ob 
diese Annahmen und Methoden im Zeitalter des Klimawandels noch gelten, wird in der wissenschaftlichen Literatur gegenwärtig kontrovers diskutiert [36, 37].

Regenmenge und damit Abflussvolumen und Abflussscheitel hängen aber nicht nur vom Wiederkehrintervall des Regens, sondern auch von der betrachteten Regendauer und der zeitlichen Verteilung des (Bemessungs-) Regens ab. Innerhalb eines Tages fällt bei gleichem Wiederkehrintervall mehr Regen als innerhalb einer Stunde; allerdings sinkt gleichzeitig die mittlere Intensität. Daher muss auch die Regendauer je nach Fragestellung festgelegt werden.

$\mathrm{Da}$ die Regenmenge, die möglich ist, mit zunehmender Regendauer zunimmt (- Tab. 4.3), ist für Fälle, in denen es auf die maximal mögliche Abflussmenge ankommt, aber nicht auf die Abflussrate, ein langdauernder Regen zu wählen. Regenperioden, die viel Regen bringen, ohne dass mehrtägige Unterbrechungen auftreten, in denen der Boden wieder abtrocknet, dauern unter deutschen klimatischen Bedingungen selten länger als drei Tage. Soll der Gesamtabfluss des größten Regens einer bestimmten Jährlichkeit bestimmt werden, kann beispielsweise der KOSTRA-Niederschlag für die Dauerstufe $72 \mathrm{~h}$ verwendet werden.

Während mit zunehmender Regendauer die Regenmenge zunimmt, nimmt gleichzeitig die Regenintensität ab. Ist man also an der höchsten Abflussrate interessiert, wählt man eine möglichst kurze Regendauer. Sie richtet sich nach der Konzentrationszeit des Einzugsgebietes. Wird die mittlere Konzentrationszeit eines Gebietes beispielsweise auf 110 min geschätzt, sollte die Dauerstufe (D) des Bemessungsregens möglichst dieser Konzentrationszeit entsprechen, z. B. $\mathrm{D}=120 \mathrm{~min}$ bei KOSTRA [35]. Wird von diesem Vorgehen abgewichen und bei einer Konzentrationszeit von $110 \mathrm{~min}$ beispielsweise ein Modellregen mit einer Dauerstufe von $4 \mathrm{~h}$ gewählt, resultiert ein höheres Abflussvolumen, aber ein geringerer Wellenscheitel, da einerseits zwar die Regenmenge zunimmt, andererseits die mittlere Regenintensität mit zunehmender Regendauer aber abnimmt. Der Regen, der zum höchsten Abflussscheitel führt, muss jedoch nicht notwendigerweise ein anderer Regen sein, als der der zum größten Abflussvolumen führt. Die hochintensiven Regen kurzer Dauer sind im Normalfall keine eigenständigen Regen, sondern Intensitätsspitzen, die eingebettet sind in einen länger andauernden Regen mit mehr Niederschlag.

Bei technischen Bauwerken richtet sich die Wahl des Bemessungsregens nach der Aufgabenstellung und variiert zwischen den Bundesländern. Kanalnetze werden beispielsweise oft für einen 5-jährlichen 5-minütigen Starkregen ausgelegt. In München entspricht das z. B. $15 \mathrm{~mm}$ in $5 \mathrm{~min}$ und bedeutet, dass alle Regen mit geringerer Intensität schadlos

- Tab.4.3 Maximale Niederschlagsmengen (in $\mathrm{mm}$ ) je Dauerstufe (D), die statistisch einmal in 1, 10, 30, 50 und 100 Jahren (Wiederkehrintervall $T_{n}$ ) im Tertiärhügelland nördlich von Freising erwartet werden können (KOSTRA-DWD, Version 2010R)

\begin{tabular}{|c|c|c|c|c|c|c|c|c|}
\hline & \multicolumn{8}{|c|}{ Dauerstufe D } \\
\hline & $5 \mathrm{~min}$ & $20 \mathrm{~min}$ & $30 \mathrm{~min}$ & $1 \mathrm{~h}$ & $3 \mathrm{~h}$ & $6 \mathrm{~h}$ & $24 \mathrm{~h}$ & $72 \mathrm{~h}$ \\
\hline$T_{n}=1$ & 6 & 12 & 14 & 17 & 23 & 28 & 39 & 58 \\
\hline$T_{n}=10$ & 14 & 25 & 29 & 34 & 40 & 45 & 70 & 101 \\
\hline$T_{n}=30$ & 18 & 31 & 35 & 42 & 51 & 56 & 85 & 123 \\
\hline$T_{n}=50$ & 20 & 34 & 38 & 46 & 55 & 62 & 92 & 132 \\
\hline$T_{n}=100$ & 23 & 38 & 43 & 52 & 57 & 61 & 95 & 143 \\
\hline
\end{tabular}


über das Kanalnetz abgeführt werden können müssen. Erst bei selteneren Ereignissen mit höheren Intensitäten werden eine Überlastung und das Überlaufen des Kanalnetzes in Kauf genommen. Beim Hochwasserschutz ist das 100-jährliche Abflussereignis $\left(\mathrm{HQ}_{100}\right)$ ein weitverbreitetes Dimensionierungsziel. Für die Festsetzung von Überschwemmungsgebieten ist es sogar im $\$ 76$ des Wasserhaushaltsgesetzes festgelegt, wodurch es bundesweit gilt. Weitere, beispielsweise in Bayern etablierte Bemessungsziele sind häufige Hochwasser $\left(\mathrm{HQ}_{\text {häufig }}\right)$, die statistisch betrachtet im Mittel alle 5 bis 20 Jahre auftreten, und Extremhochwasser $\left(\mathrm{HQ}_{\text {extrem }}\right)$, das $\mathrm{zu}$ deutlich höheren Wasserständen als ein $\mathrm{HQ}_{100}$ führt und seltener auftritt. Als $\mathrm{HQ}_{\text {extrem }}$ wird in Bayern die 1,5-fache Abflussmenge des $\mathrm{HQ}_{100}$ angenommen [38]. Für die Bemessung kritischer Infrastrukturbauwerke wie die Notentlastung von Talsperren oder die Standsicherheit der Dämme großer Hochwasserrückhaltespeicher werden Bemessungsziele wie $\mathrm{HQ}_{1000}$ oder $\mathrm{HQ}_{10000}$ herangezogen. In Baden-Württemberg basieren Bemessungsziele weitgehend auf dem Regen und nicht auf dem Abfluss, was deutlich einfacher ist, weil die Niederschlags-Abfluss-Beziehung nicht bekannt sein muss. Der Leitfaden zum kommunalen Starkregenrisikomanagement [39] definiert Regen als selten, wenn sie eine Jährlichkeit von mehr als 30 Jahren haben. Als außergewöhnlich und als Auslöser von Sturzfluten gelten dort Regen, die eine Jährlichkeit von mindestens 100 Jahren haben.

Für ländliche Räume sind die im technischen Hochwasserschutz verbreiteten Bemessungsniveaus wie 100-jährliche Abflüsse oder Regen unangemessen, da sich aus der dünnen oder fehlenden Besiedelung und der Abwesenheit höherer Vermögenswerte in den Außenbereichen grundsätzlich geringe Schutzbedürfnisse ergeben als in besiedelten, kommunalen Räumen. Hinzu kommt, dass bei der Wahl sehr seltener Extreme (Wiederkehrintervalle > 50 Jahre) schnell enorme Abflussmengen und Scheitelhöhen erreicht werden, deren Minderung oft aufwendige, teure und flächenintensive Maßnahmen erfordert. Gleichzeitig verursachen kleinere, aber häufiger auftretende Extreme in Summe ebenfalls etwa die Hälfte aller Schäden, die sich mit dezentralen Ansätzen zum Wasserrückhalt dagegen wirksam beeinflussen ließen. Daher werden für die Dimensionierung von Maßnahmen für den ländlichen Hochwasserschutz Bemessungsziele in der Größenordnung von 20 bis 30-jährlichen Ereignissen empfohlen.

Anhand des KOSTRA-Datensatzes lassen sich für beliebige Orte in Deutschland Bemessungsniederschlagshöhen ermitteln. Die Wahl der Niederschlagsdauerstufe richtet sich dabei nach der Zielstellung. Zur Ermittlung des größtmöglichen Abflussscheitels sollten verschiedene Regendauerstufen untersucht und verglichen werden. Üblicherweise ergibt sich der höchste Abflussscheitel für Regen, deren Dauer der Konzentrationszeit des Gebietes entspricht, da die Niederschlagsintensität mit zunehmender Regendauer abnimmt. Da überschlägige Abschätzungen für Maßnahmen in der Flur häufig hinreichend sind, kann vereinfachend auch von einem kurzen, wolkenbruchartigen Schauer mit einer Dauer von 1 bis $4 \mathrm{~h}$ ausgegangen werden, ähnlich dem Leitfaden zum kommunalen Starkregenrisikomanagement aus Baden-Württemberg [39]. Müssen Ganglinien erzeugt werden, wird am besten ein mittenbetonter Regenverlauf unterstellt. Details zur Ableitung von Modellregen sind in $>$ Anhang 8.4 beschrieben.

\subsubsection{Niederschlagshöhen typischer Starkregenereignisse nach KOSTRA}

Der KOSTRA-Datensatz [35] ist eine amtliche Bemessungsgrundlage zu erwartender Extremregen des Deutschen Wetterdienstes (DWD). Bei KOSTRA wurden durch statistische Auswertung langjähriger historischer Zeitreihen von 100 (teilweise 150) Regenmessstationen 
(Punktmessungen) aus ganz Deutschland Niederschlagshöhen (in $\mathrm{mm}$ ) und -spenden (in $1 \mathrm{~s}^{-1} \mathrm{ha}^{-1}$ ) in Abhängigkeit verschiedener Jährlichkeiten $\left(\mathrm{T}_{\mathrm{n}}\right.$ ) (1 a bis 100 a) und Regendauerstufen (D) (5 min bis $72 \mathrm{~h}$ ) bestimmt. Von Regendauerstufen spricht man, weil Niederschläge nicht für eine beliebige Regendauer angegeben sind, sondern die Regendauer in Stufen eingeteilt worden ist, die für praktische Belange hinreichend differenziert sind. Die Daten liegen in einem Rasternetz (Maschenweite ca. $67 \mathrm{~km}^{2}$ ) deutschlandweit als Planungsgrundlage für den (ländlichen) Hochwasserschutz vor. Der KOSTRA-Datensatz (Version 2010R) kann über das Climate Data Center des DWD [40] kostenfrei bezogen werden. Ab 2020 wird voraussichtlich auch eine Abschätzung von Extremwerten auf Basis der Radarklimatologie verfügbar sein. Aus ersten Vergleichen zeichnet sich ab, dass die Radardaten sowohl die Intensitäten als auch die räumliche Verteilung kurzer konvektiver Starkregenereignisse anders einstufen als die auf dem Bodenmessnetz basierenden KOSTRA-Daten [41, 42]. Dies liegt an der unterschiedlichen räumlichen Auflösung der Messung [43], wobei die Auflösung des Wetterradars $\left(1 \mathrm{~km}^{2}\right)$ besser für die Skala von Einzugsgebieten geeignet ist als die Auflösung von Regenmessern $\left(200 \mathrm{~cm}^{2}\right)$. Daher werden Daten von Regenmessern oft mit sogenannten Flächenreduktionsfaktoren auf die Größe des Einzugsgebietes skaliert [44-46].

Die KOSTRA-Daten decken nur den Zeitraum von Mai bis September ab. Dies ist sowohl für die Wahl der größten Niederschlagsintensität wie auch für die größte Niederschlagsmenge ausreichend, da in den Wintermonaten kaum mehr Intensität oder Menge auftritt. In den Wintermonaten kann es vor allem dann zu hohen Abflussintensitäten oder Abflussvolumina kommen, wenn warmer Regen auf eine Schneedecke fällt und dadurch Schmelzwasser hinzukommt. Zur Einschätzung dieser kombinierten Effekte ist KOSTRA aber ungeeignet. Stattdessen kann der REWANUS Datensatz (siehe Anhang 8.4.5) verwendet werden.

\section{Beispiel der KOSTRA-Daten}

Zur Illustration wurden die KOSTRA-Werte

für unterschiedliche Dauerstufen und Jährlichkeiten für das landwirtschaftlich intensiv genutzte Tertiärhügelland nördlich von Freising in Bayern in 0 Tab. 4.3 zusammengestellt. Die Werte zeigen, dass im Mittel alle 30 Jahre mit einem Niederschlag von rund $50 \mathrm{~mm}$ innerhalb von drei Stunden zu rechnen ist. Eine Planung, die auf diese Niederschlagshöhe abzielt, lässt alle Niederschlagshöhen beherrschen, die häufiger als einmal in 30 Jahren auftreten, also die meisten Niederschläge. Sie nimmt allerdings auch in Kauf, dass ein Niederschlag, der im Mittel nur einmal alle 50 oder 100 Jahre auftritt, nicht mehr beherrscht wird.

Die in - Tab.4.3 zusammengestellten Daten sind für weite Teile Deutschlands repräsentativ (zum Vergleich; der deutsche Mittelwert für $\mathrm{D}=1 \mathrm{~h}$ und $\mathrm{T}_{\mathrm{n}}=30$ a beträgt $41 \mathrm{~mm}$, der für das Tertiärhügelland $42 \mathrm{~mm}$; s. auch - Abb.4.7). Die Größenordnung von $50 \mathrm{~mm}$ kann also als Faustwert für viele planerische Maßnahmen zur Starkregenvorsorge angesetzt werden. Innerhalb Deutschlands variieren die vom Bodenmessnetz erfassten Starkniederschlagshöhen bei kurzen Dauerstufen etwa um den Faktor zwei, wobei ein Gradient vom Norddeutschen Tiefland hin zu höheren Lagen (Alpenraum, Mittelgebirgslagen) vorhanden ist. Mit zunehmender Dauerstufe werden regionale Unterschiede kleiner und nur noch Höhenlagen über $1000 \mathrm{~m}$ erzeugen ein Muster. Die räumlichen Muster für 1- und 4-stündige Regen zeigt • Abb. 4.7 am Beispiel einer Jährlichkeit von 30 Jahren.

Die KOSTRA-Daten erlauben keine Beurteilung des Jahresgangs. Die höchsten Intensitäten und größten Mengen treten üblicherweise im Juli oder August auf, aber dies ist aus den Daten nicht ersichtlich. Soll ein Jahresgang ermittelt werden oder sollen 
nicht Extremwerte sondern typische Werte oder Monatssummen und Ähnliches ermittelt werden, eignen sich die KOSTRA-Daten nicht mehr. In diesen Fällen sollte auf Niederschlagszeitreihen zurückgegriffen werden. Dabei ist allerdings $\mathrm{zu}$ beachten, dass das CN-Modell kein Tagesmodell sondern ein Ereignismodell ist. Daher sollten mehrere aufeinanderfolgende Regentage als ein Ereignis betrachtet werden. Dies wird im $>$ Anhang 8.10 exemplarisch belegt.

Kommt es darauf an, die Abflussdisposition bei typischen, im Jahresverlauf variierenden Ereignisstärken zu vergleichen, z. B. um verschiedene Bewirtschaftungsoptionen zu bewerten, ist eine Differenzierung nach Monaten notwendig. Will man dafür nicht langjährige Niederschlagszeitreihen

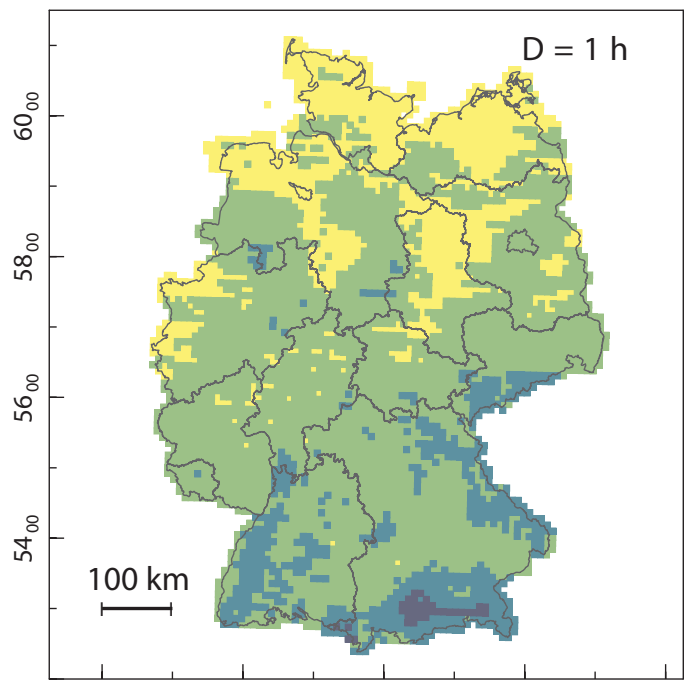

Niederschlagshöhe $(\mathrm{mm})$
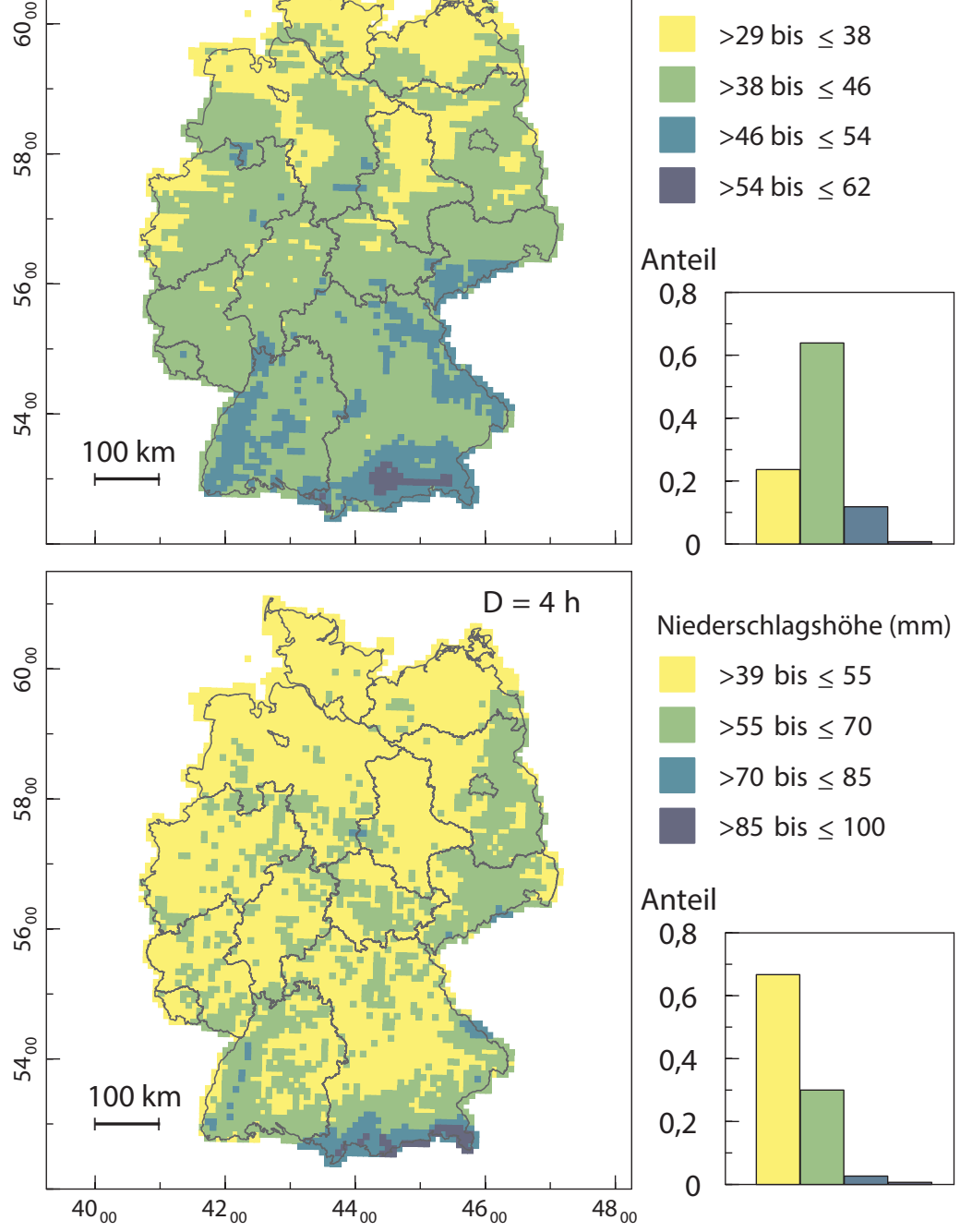

Niederschlagshöhe $(\mathrm{mm})$
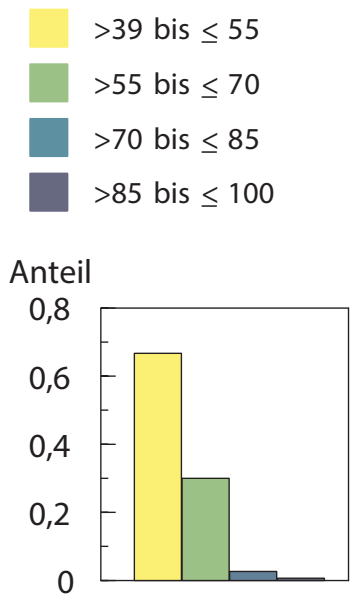

- Abb. 4.7 Starkniederschlagshöhen in mm mit einer Jährlichkeit $T_{n}$ von 30 Jahren für die Dauerstufen $D$ von 1 und $4 \mathrm{~h}$. Die jeweilige Spannweite wurde in vier gleich große Intervalle geteilt 
- Tab. 4.4 Jahresgang typischer mittlerer Ereignisniederschlagsmengen (in $\mathrm{mm}$ ). Der Augustniederschlag entspricht etwa dem 1-jährlichen 72-h-Regen oder dem 30-jährlichen 6-h-Regen der KOSTRA-Daten

\begin{tabular}{|l|l|l|l|l|l|l|l|l|l|l|l|l|}
\hline Monat & Jan & Feb & Mär & Apr & Mai & Jun & Jul & Aug & Sep & Okt & Nov & Dez \\
\hline $\begin{array}{l}\text { Nieder- } \\
\text { schlag }\end{array}$ & 35 & 30 & 35 & 40 & 45 & 50 & 55 & 60 & 55 & 50 & 45 & 40 \\
\hline
\end{tabular}

durchrechnen, eignen sich für diesen Zweck die Ereignisniederschläge, die auch hier z. B. in - Abb. 4.14 bis 4.17 unterstellt wurden. Sie sind in - Tab. 4.4 zusammengestellt.

\subsection{Ansatzpunkte zur Reduktion des Abflussvolumens}

\subsubsection{Landnutzungsänderung}

Für einen Regen mit einer Niederschlagshöhe von $40 \mathrm{~mm}$ variiert die Abflusshöhe stark je nach Landnutzungstyp, aber auch nach Jahreszeit (• Abb.4.5). Dies macht die Beurteilung schwierig, welche Landnutzung um wie viel besser oder schlechter ist als eine andere Landnutzung. Mittelt man alle Monate des Jahres, dann zeigt sich, dass leguminosenbasiertes mehrjähriges Ackerfutter ganz besonders stark den Abfluss mindern kann (- Abb. 4.8, linke Balken), wenn man die sehr niedrigen $\mathrm{CN}$-Werte von [18] zugrunde legt, die experimentell gut abgesichert sind. Würde man die älteren, in vielen $\mathrm{CN}$-Tabellen enthaltenen Werte verwenden, wäre der Abfluss immer noch niedrig, aber eher wie der von Grünland. Besonders hohe Abflüsse sind dagegen von Verkehrsflächen, aber auch von Siedlungsgebieten $\mathrm{zu}$ erwarten. Gegenüber dem Bereich, der von mehrjährigem Ackerfutter und Verkehrsflächen aufgespannt wird, sind die Unterschiede der übrigen Landnutzungen vergleichsweise moderat. Reihenkulturen weisen einen etwas höheren Abflussanteil auf, während der Abflussanteil von Getreide etwas niedriger, der von Wald und Grünland deutlich niedriger ist. Eine
Änderung der Kulturartenzusammensetzung innerhalb der Ackerflächen hat also einen vergleichsweise geringen Effekt. Eine Änderung der Bewirtschaftungsweise wirkt wesentlich stärker (vgl. - Abb. 4.6). Eine Ausweitung des Grünlandes oder des Waldes zu Lasten der Ackerflächen verringert den Abfluss noch etwas stärker. Dieser Effekt ist durch unterschiedliche Studien belegt, z. B. [47].

Es ist wichtig, darauf hinzuweisen, dass diese Verhältnisse nur im Mittel des Jahres und nur für den angenommenen 40-mm-Regen gelten. In den einzelnen Monaten können die Verhältnisse deutlich anders sein. Im Frühsommer, wenn die Reihenkulturen ihre kritische Phase haben, tragen sie wesentlich mehr zum Gesamtabfluss bei, während das Getreide seine kritische Phase eher im Spätsommer bis in den Winter hat (• Abb. 4.5). Bei kleineren Regen wäre der Anteil der Verkehrsund Siedlungsflächen sogar noch wesentlich höher als bei dem 40-mm-Regen, weil dann andere Landnutzungen kaum noch Abfluss erzeugen, während der Anteil der Verkehrsund Siedlungsflächen bei noch größeren Regen etwas sinkt, auch wenn ihr Gesamtabfluss natürlich steigt.

Zusätzlich zu der innerhalb eines Jahres auftretenden Variabilität unterliegt die Landschaft dem Wandel der Zeit. Zur Veranschaulichung und Quantifizierung dieser Veränderungen wurde die aktuelle Flächennutzung eines $2,6 \mathrm{~km}^{2}$ großen Landschaftsausschnitts nördlich von Freising in Bayern bei Zolling im Tertiärhügelland erfasst und der Flächennutzung von 1858 und 1973, die aus historischen Karten rekonstruiert wurde, gegenübergestellt (• Abb. 4.9). Der 


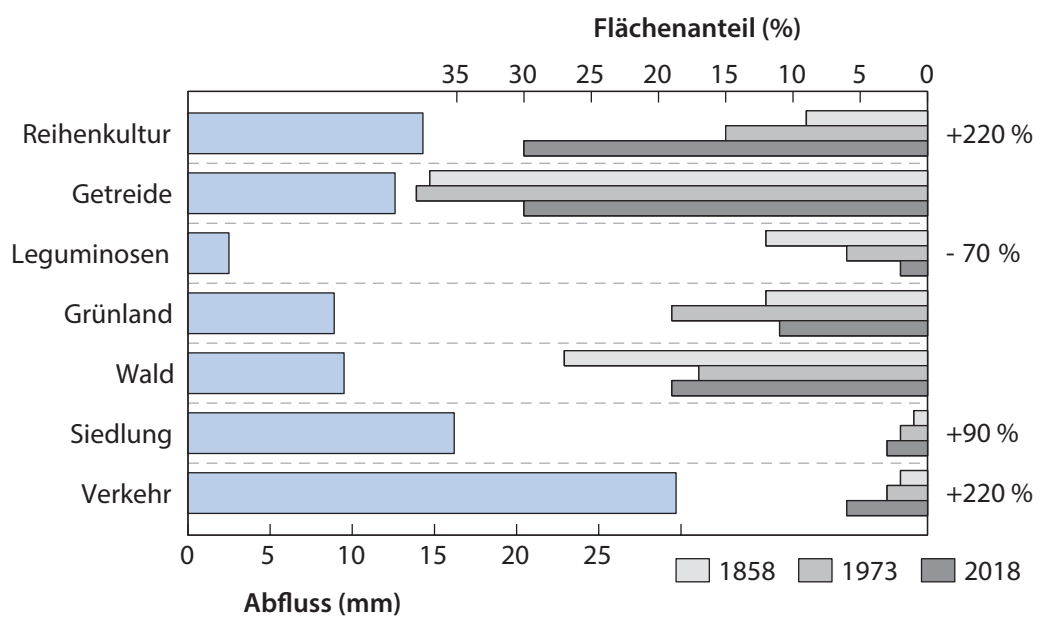

- Abb. 4.8 linke Balken: Mittlerer Abfluss verschiedener Landnutzungen bei einem 40-mm-Regen (Mittelwerte des Jahresgangs aus - Abb. 4.5). Rechte Balken: Änderung der Flächenanteile verschiedener Landnutzungen zwischen 1858 und 2018 für das Modellgebiet Zolling; die Prozentangaben neben der rechten Achse geben die Veränderung der Flächenanteile bezogen auf 1858 für Nutzungen wieder, bei denen ein besonders starker Trend vorliegt

Vergleich der Jahre 1858 und 2018 zeigt eine geringfügige Zunahme der Ackerfläche von 58 auf 62 ha (6\%), während der Anteil der Grünlandflächen um den gleichen Prozentsatz abgenommen hat. Deutlicher als die Veränderung des Ackeranteils ist die Veränderung der Kulturartenverteilung innerhalb der Ackerflächen. Dabei konnten die aktuellen Zahlen aus den Statistiken für dieses Gebiet entnommen werden, während die Kulturartenverteilung für 1858, wie von [48] allgemein für diese Zeit angegeben, angenommen wurde. Demnach ist vor allem der Anteil des mehrjährigen, leguminosenbasierten Ackerfutters (Kleegras, Luzerne u. Ä.) von $20 \%$ auf etwa $4 \%$ der Ackerfläche zurückgegangen, weil Leguminosen durch die Einführung der Mineraldüngung ihre Bedeutung als Stickstoffquelle verloren haben. Dagegen hat der Anteil der Reihenkulturen sehr stark von $16 \%$ auf nahezu die Hälfte der Ackerfläche zugenommen (rechte Balken in Abb. 4.8; dort allerdings in Prozent der Gesamtfläche), da nun nicht mehr das mehr- jährige Ackerfutter über die Rinderfütterung verwertet und der Stickstoff als Wirtschaftsdünger nutzbar gemacht werden muss, sondern Mais zum wesentlichen Futtermittel avancierte.

Ebenfalls deutlicher als die Veränderung der Flächenanteile von Acker und Grünland ist die Veränderung ihrer räumlichen Verteilung. Wie - Abb. 4.9 zeigt, werden heute einige Steilflächen im Südwesten (Gefälle 9-20\%) als Grünland genutzt, die in der Karte von 1858 noch als Ackerflächen ausgewiesen waren. Dafür sind fast alle Grünlandflächen in den nach Osten gerichteten Tiefenlinien verschwunden und Ackerflächen gewichen. Diese Veränderung ist nicht nur für das Tertiärhügelland in Bayern, sondern für große Teile fruchtbarer, heute landwirtschaftlich intensiv genutzter Gebiete Deutschlands typisch, wie Publikationen aus Sachsen [49] und Bayern [50] zeigen. Ebenfalls sehr deutliche Änderungen in den Flächenanteilen gab es im Modellgebiet bei Wald- und Heckenflächen, die abgenommen 

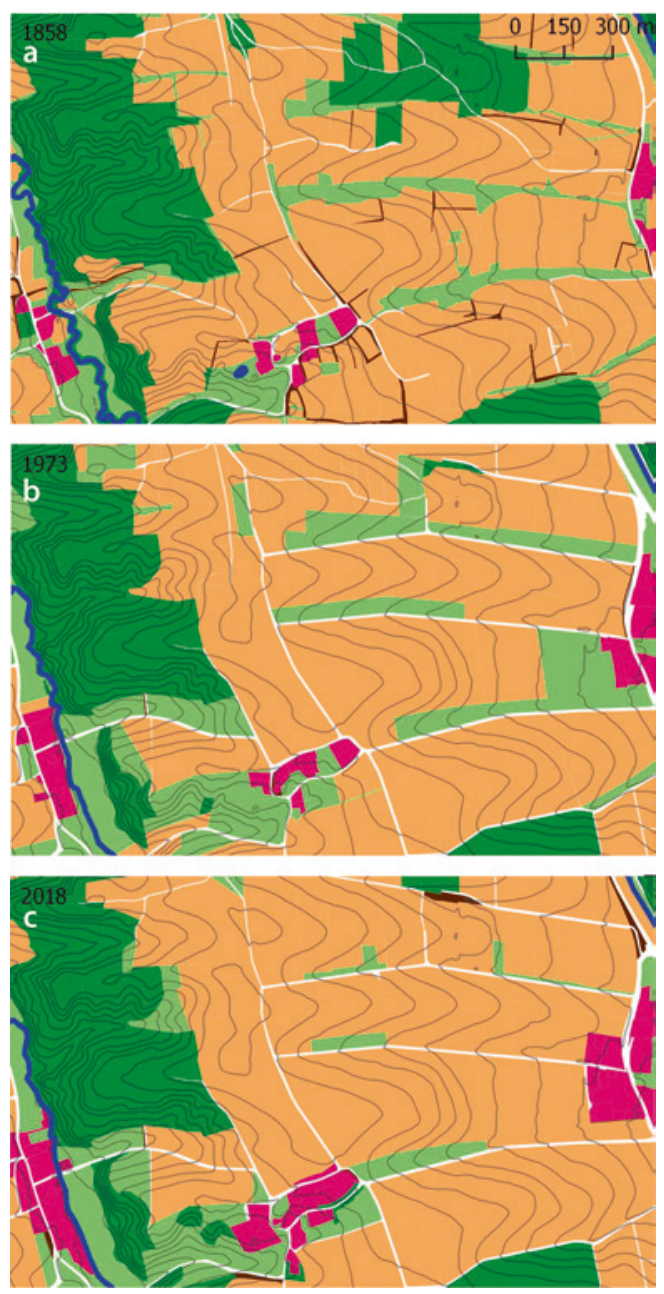

- Abb. 4.9 Veränderung der Flächennutzung in einem 258 ha großen Landschaftsausschnitt $(2 \times 1,3 \mathrm{~km})$ bei Zolling, nördlich von Freising im Tertiärhügelland seit 1858. Dargestellt sind Wald- und Forstflächen (dunkelgrün), Grünland (hellgrün), Acker (orange) und Siedlungsflächen (magenta). Der Verlauf von Heckenzügen (dunkelbraun) ist in der Uraufnahme von 1858 a vermerkt, der aktuelle Zustand b waren keine Daten verfügbar. Die Topographie ist durch 5-m-Höhenlinien (graue Linien) dargestellt c wurde durch Kartierung im Gelände und Luftbildauswertung erfasst 1973 (Datenquelle: Geobasisdaten der Bayerischen Vermessungsverwaltung, teilweise durch Kartierungen ergänzt)

haben, sowie bei Siedlungs- und Verkehrsflächen die um 90 \% bzw. $220 \%$ zugenommen haben (• Abb. 4.8, rechte Balken). Die Länge des Wegenetzes stieg im betrachteten Zeitraum von rund $11 \mathrm{~km}$ auf $14 \mathrm{~km}$, wobei die früher vorhandenen Pfade und Grünwege (teilweise als weiße Flächen in - Abb. $4.9 \mathrm{zu}$ erkennen) im Rahmen der Flurbereinigung in den 1960er- bis 1980er-Jahren überwiegend in ihrem Verlauf verändert und durch asphaltierte Feldwege ersetzt wurden. Die durch Straßen versiegelte Fläche beträgt heute etwa 2,6 ha, alle Ost-West-orientierten Wege verlaufen in oder nahe von Tiefenlinien.

In der Summe hat es also eine Vielzahl von Veränderungen in der Landnutzung gegeben. Insbesondere ist problematisch, dass der stärkste Rückgang im Flächenanteil beim mehrjährigen Ackerfutter zu verzeichnen ist, das von allen Landnutzungen weitaus am wenigsten Abfluss erzeugt. Gleichzeitig haben die Landnutzungen, die besonders viel Abfluss erzeugen, vor allem Verkehrs- und Siedlungsflächen, aber auch Reihenkulturen, stark zugenommen (• Abb. 4.8). Von daher ist eine starke Änderung im Abflussvolumen zu erwarten. Die Berechnung, wenn die linken und die rechten Balken in - Abb. 4.8 verknüpft und das Ergebnis addiert wird, zeigt aber nur eine recht moderate Zunahme des Abflussvolumens von etwa $20 \%$ (• Abb. 4.10). Dies liegt daran, dass sich die Effekte teilweise kompensieren. Die Ausweitung der Reihenkulturen erhöht zwar ihren Anteil am Gesamtabfluss stark, da gleichzeitig auch der Anteil des Getreides sinkt, erhöht sich die Summe aus den Abflussanteilen von Reihenkulturen und Getreide nur moderat. Nur der Einfluss der Ausweitung der Verkehrs- und Siedlungsflächen auf den Gesamtabfluss ist deutlich. Dagegen kann selbst bei einer radikalen Änderung der Nutzung land- und forstwirtschaftlicher Flächen, z. B. durch deutliche Verringerung des Ackeranteils oder des Anteils von Reihenkulturen zugunsten von Getreide, das Abflussvolumen nur relativ wenig verändert werden. Wesentlich stärker lässt sich das Abflussvolumen einer Landschaft durch die landwirtschaftliche Bewirtschaftungspraxis vermindern, da dabei diese kompensatorischen Effekte nicht auftreten. 


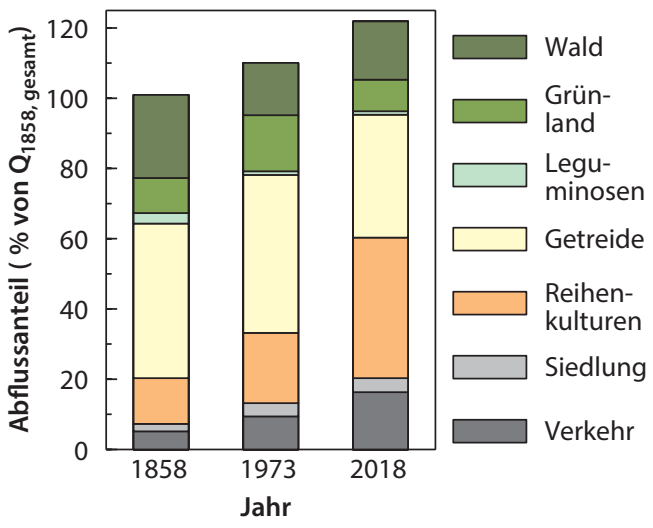

- Abb. 4.10 Veränderung der Abflussanteile in einem 2,6 km² großen Einzugsgebiet im Tertiärhügelland nördlich von Zolling für drei unterschiedliche Zeitpunkte. Die Abflussanteile sind relativ zum Gesamtabfluss von 1858 angegeben und über das Jahr gemittelt. Leguminosen steht für mehrjähriges, leguminosenbasiertes Ackerfutter

Werden die Reihenkulturen beispielsweise in Mulchdirektsaat angebaut ( Abschn. 4.5.3), wirkt sich die Abflussminderung voll aus, weil diese Änderung in der Bewirtschaftung nicht mit Änderungen bei anderen Landnutzungen einhergeht. Vor allem aber folgt aus dieser Auswertung die Notwendigkeit, Maßnahmen zum Bremsen des Abflusses entlang des Fließpfades zwischen Wasserscheide und Gewässernetz zu ergreifen (s. \ Kap.6), um den Abflussscheitel zu dämpfen, da die Möglichkeiten der Verminderung der Abflussmenge begrenzt sind.

\subsubsection{Flächenparzellierung}

Aus der im Jahresverlauf stark wechselnden Abflussdisposition verschiedener Kulturarten (- Abb. 4.5) folgt, dass eine vielfältige Landnutzung in einem Einzugsgebiet extreme Abflüsse zu bestimmten Zeitpunkten vermeidet, zu denen eine bestimmte Kultur gerade ihre besonders abflussanfällige Phase hat. Eine vielfältige Landnutzung ist aber nur dadurch $\mathrm{zu}$ erreichen, wenn die einzelnen Landnutzungsparzellen nicht zu groß werden. Kleinteilige Schlagstrukturen verursachen fast immer eine heterogene Nutzung der Fläche (insbesondere bei heterogenen Eigentumsverhältnissen). Damit geht eine hohe räumliche (und zeitliche) Variabilität der Oberflächenabfluss liefernden Flächen einher [51]. Ist dies gegeben, kann ein weiterer Effekt hinzukommen, die sogenannte Runon-Infiltration $[52,53]$. Diese tritt auf, wenn der Oberflächenabfluss einer Fläche über eine unterhalb liegende Fläche fließt, die selbst keinen Abfluss produziert, deren Infiltrationsvermögen also noch nicht ausgeschöpft ist. Die Runon-Infiltration kann besonders bei kleineren und mittleren abflusswirksamen Regen den Gesamtabfluss vermindern, weil bei solchen Regen das Infiltrationsvermögen noch nicht auf allen Flächen ausgeschöpft ist. Bei sehr großen Regen, bei denen alle Flächen liefern, kommt der Effekt dagegen zum Erliegen und es bleibt nur der Effekt, dass die Heterogenität der Landnutzung Extreme vermeidet.

Der Effekt der Runon-Infiltration wurde u. a. in Modellstudien im Weiherbachgebiet in Baden-Württemberg nachgewiesen [54]. Dort trugen jeweils lediglich diejenigen Ackerschläge zum Abfluss bei, die wegen geringer Bedeckung zum Zeitpunkt des Regens leicht verschlämmt. Bei einem Regen im Frühsommer waren dies Maisanbauflächen, bei einem Regen im Sommer waren es Mais, Sonnenblumen und Gemüse zu etwa gleichen Teilen und bei einem Regen im Spätsommer waren nur noch Gersten- und Gemüseschläge betroffen (• Abb.4.11). Die übrigen Flächen nahmen dagegen je nach Lage und Überströmung einen Teil des von den genannten Kulturen stammenden Abflusses wieder auf, sodass Mais, der im Frühsommer als wesentlicher Abflusslieferant wirkte, im Spätsommer Abfluss von Nachbarflächen infiltrierte. 


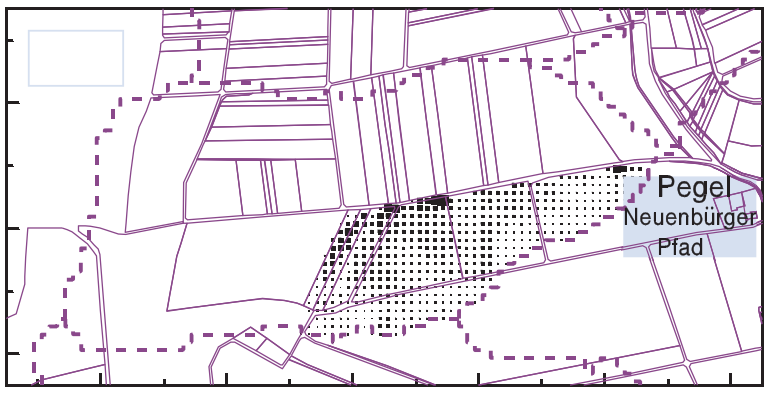

Ereignis:

21. 7. 1992

abflusswirksam:

Mais

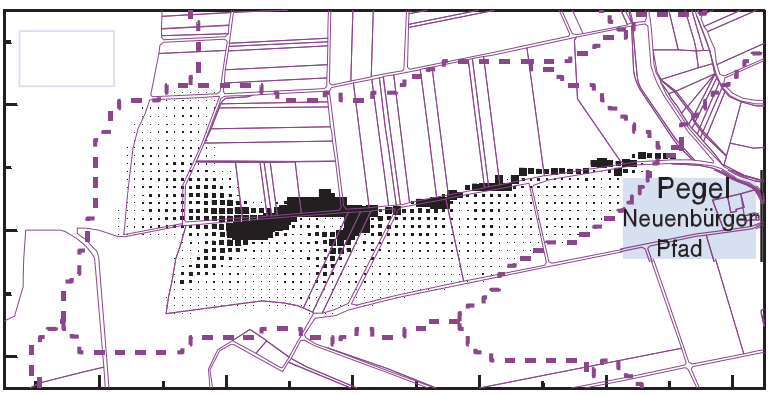

Ereignis:

27. 6. 1994

abflusswirksam:

Mais

Gerste

Gemüse

Sonnenblumen

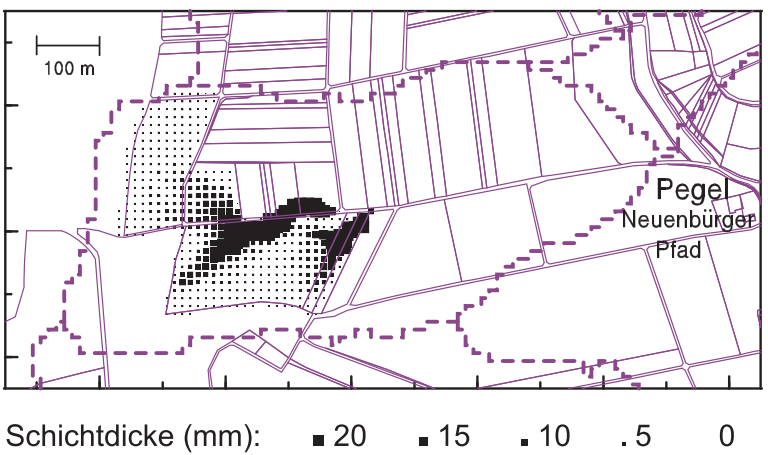

Ereignis:

12. 8. 1994

abflusswirksam:

Gerste

Gemüse

(Sonnen-

blumen)

- Abb. 4.11 Intensität und jahreszeitliche Varianz der zum Oberflächenabfluss beitragenden Flächen, ausgedrückt durch die berechnete Schichtdicke des Abflusses für drei Ereignisse im Einzugsgebiet Neuenbürger Pfad, Weiherbach [54]

Runon-Infiltration durch Streifenanbau Der Effekt der Runon-Infiltration wird im Streifenanbau gezielt genutzt, der aber in Mitteleuropa im Gegensatz zu den USA nicht verbreitet ist (sogenanntes Strip-cropping oder Strip-farming, das nicht mit Streifenbearbeitung, englisch "strip-tillage" zu verwechseln ist), das aber von der Europäischen Kommission wegen der vielfältigen günstigen Wirkungen empfohlen wird [55]. Durch die sehr starke Zusammenlegung von Flächen könnte Streifenanbau inzwischen auch in Europa praktiziert werden. Dabei wird eine sehr große Fläche mit zwei Kulturen bebaut, die sich in regelmäßigen Streifen quer zur Hauptgefällerichtung abwechseln. Dies ist arbeitswirtschaftlich vorteilhaft, da weiterhin große Einheiten bleiben, wenn die Streifen ein Mehrfaches der Maschinenarbeitsbreite betragen, da dann alle mit einer Kultur bestandenen Streifen gleichzeitig und ohne Mehraufwand bewirtschaftet werden können. Die Streifen dürfen aber nicht breiter als eine kritische Hanglänge sein, die vom 
Gefälle abhängt. Sie gilt gleichermaßen für die Erosionsvorsorge und kann nach > Gl. 6.1 in > Abschn. 6.1 ermittelt werden. Für übliche Gefälleneigungen von 4 bzw. $8 \%$ ergeben sich kritische Hanglängen von rund 100 bzw. 60 m (vier Maschinenbreiten bei Düngestreuern entsprechen häufig $60 \mathrm{~m}$ ). Damit wird erreicht, dass der Abfluss von einem Streifen breitflächig in den nächsten Streifen fließt und dort möglichst vollständig versickert.

Der Streifenanbau vermindert nicht nur den Oberflächenabfluss, sondern ist auch ein effizientes Mittel zur Erosionsminderung [56]. Die Wirkung eines Fruchtartenwechsels am Hang ist anhand von Luftbildaufnahmen nach Starkregenereignissen gut zu erkennen [57]. Im Vergleich $\mathrm{zu}$ einem einheitlichen, nicht untergegliederten Maisfeld zeigen sich dort deutlich geringe Erosionsrinnen und
Stoffaustragsspuren (• Abb. 4.12), auch wenn die Nutzung in dem Fall die Bedingungen eines echten Streifenanbaus noch nicht erfüllt hatte.

Als Alternative zum Streifenanbau, der große Gewanne voraussetzt, lässt sich die Runon-Infiltration nutzen, wenn die Tiefenlinien begrünt sind, in denen der Abfluss sich sammelt und über eine lange Strecke weiterfließt. Bei langjährigen Versuchen im Klostergut Scheyern wurde gemessen, dass in einem 15-20 m breiten und mehrere $100 \mathrm{~m}$ langen Grasstreifengerinne für einzelne Ereignisse bis $\mathrm{zu} 45 \%$ des in den angrenzenden Äckern entstehenden und in den Grasstreifen entwässernden Oberflächenabflusses wieder infiltrierte [58]. In einer flächenhaften Modellierung eines großen Einzugsgebietes zeigte sich, dass in ackerbaudominierten Gebieten bereits 2,4 \% Grünland in Form von schmalen Streifen entlang der Hangmulden genügen, um im Sommer die Abflusshöhe um etwa $30 \%$ und den Scheitelabfluss um etwa $40 \% \mathrm{zu}$ reduzieren. Die Werte sind etwas

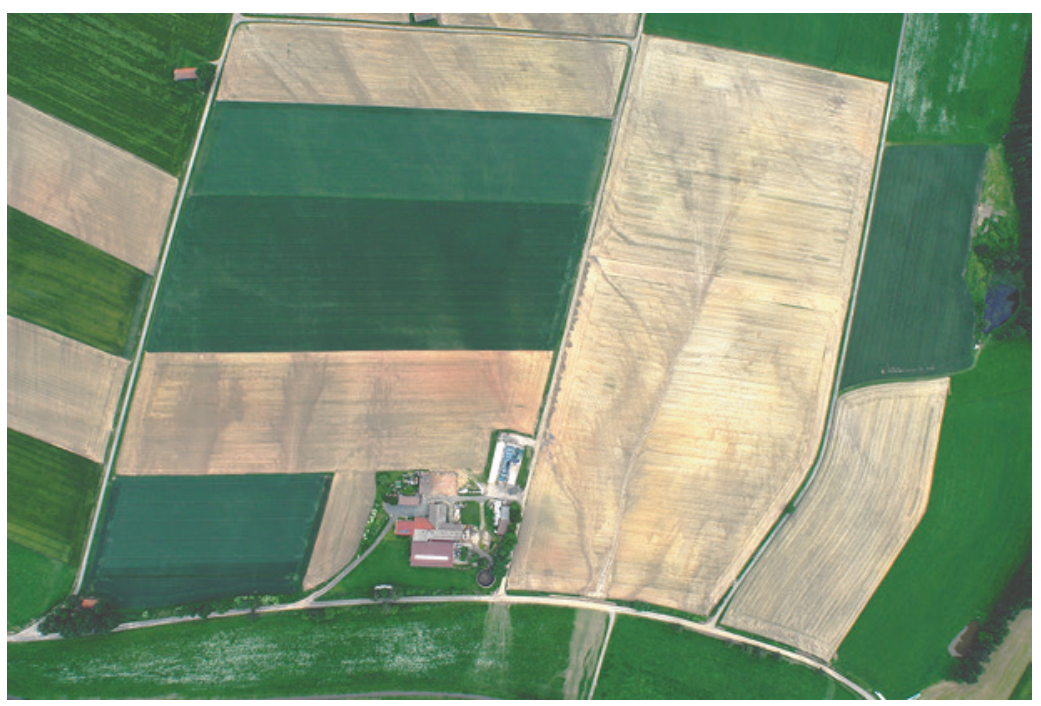

- Abb. 4.12 Luftbildaufnahme einer Hanglage nach einem Stundenniederschlag von $18 \mathrm{~mm}$ am 10.06.2011. Trotz Querbearbeitung kam es in dem langgestreckten Maisfeld (rechte Bildhälfte) zu Hangmuldenabfluss und starkem Bodenabtrag (Schwämmfächer unten rechts). In der linken Bildhälfte wurde eine stärkere Bodenerosion und die Ausbildung eines konzentrierten Hangmuldenabflusses durch den Fruchtartenwechsel und die dort auftretende, höhere Infiltration sowie die reduzierte, kritische Hanglänge verhindert (Quelle: W. Bauer, Agroluftbild) 
höher für häufig auftretende Abflussereignisse und geringer für seltene Abflussereignisse und auch geringer im Winter [9]. Das Modellgebiet Zolling zeigt, dass dies bis weit ins 20. Jahrhundert die typische Anordnung des Grünlandes war, das als schmale Bänder in den Tiefenlinien lag (• Abb. 4.9).

Aus diesen Überlegungen ergibt sich auch, dass vor allem hoch infiltrationsfähige Flächen in Gewässernähe, die bei Starkregen überflutet werden und einen Teil des Wassers durch Infiltration aufnehmen, vorteilhaft wären. Die tatsächliche Entwicklung verlief aber konträr zu diesen Überlegungen. Nach der Bodennutzungsstatistik betrug der Grünlandverlust zum Beispiel in Bayern zwischen 1960 und 2014 rund 651.000 ha [59]. Wird davon ausgegangen, dass überwiegend das Feuchtgrünland in Muldenzügen und Tallagen von der Umwidmung betroffen ist [60], entspricht dies rechnerisch dem Verlust eines $65 \mathrm{~m}$ breiten Grünlandstreifens entlang des gesamten, rund $100.000 \mathrm{~km}$ langen bayerischen Fließgewässernetzes. Gleichzeitig wurde durch die Gräben und Verrohrungen ein sekundäres Entwässerungsnetz geschaffen, das bei Oberflächenabfluss anspringt, sodass der Oberflächenabfluss am noch vorhandenen Grünland vorbeigeleitet wird.

\section{Wirkung von Terrassen}

Terrassen mindern Erosion und Oberflächenabfluss gleichermaßen

(- Abb. 4.13). Ihr Potenzial ist insbesondere bei langen Hängen groß, weniger wegen ihres Einflusses auf die Infiltration

(- Abb. 4.16), als vielmehr, weil sie den Abfluss verlangsamen. Aus gleichem Grund vermindern sie auch den Bodenabtrag, da die Transportkapazität des Abflusses stark von der Fließgeschwindigkeit abhängt. Terrassen werden seit der Antike für landwirtschaftliche Zwecke angelegt und genutzt, wobei sie sowohl in den USA als auch in China in der Mitte des 20. Jahrhunderts eine Renaissance erlebten. So gilt eine Terrassierung des Geländes auf erosionsanfälligen Standorten mit einem Gefälle $\geq 7 \%$ in den USA heute als best-management practice zum Wasser- und Stoffrückhalt [61]. Im Chinesischen Lössplateau wurden in den letzten Jahrzehnten etwa $50 \%$ der ackerbaulichen Nutzflächen mit einem Gefälle $\geq 5 \%$ terrassiert [62]. Der wesentliche Mechanismus von Terrassen besteht darin, dass die Hanglänge verkürzt und Schicht- und Rinnenerosion durch die geringere Neigung und die Verlängerung der Fließweglänge weitgehend verhindert werden kann. Neben dieser den Abfluss bremsenden Wirkung können Terrassen auch deutlich Abflussvolumen zurückhalten, wenn sie als kaskadenförmige Rückhalte- und Absetzflächen konstruiert werden. Dies wirkt gleichzeitig Trockenheit entgegen, die immer der zweite Schadmechanismus ist, wenn Niederschlag als Oberflächenabfluss abfließt. Terrassen sind daher ein sehr effektives und ganzheitliches Mittel, den Wasser- und Stoffhaushalt einer Landschaft positiv zu beeinflussen. In Deutschland sind Terrassen bis heute nur selten und vor allem auf Steilhängen, z. B. im Weinanbau, anzutreffen. Studien aus rebterrassierten Einzugsgebieten im Ostkaiserstuhl zeigen, dass der Hauptanteil des Oberflächenabflusses dort durch befestigte Wege entsteht, wobei sich der Oberflächenabfluss proportional zur Vergrößerung des versiegelten Flächenanteils erhöht [63, 64]. Eine Modellierungsstudie aus Tschechien schätzt, dass Terrassen den Scheitelabfluss 100-jährlicher Niederschläge um über $40 \%$ reduzieren können [65]. Zur Anlage von Terrassen und zur Abschätzung ihrer Wirkung auf Wasser und Erosion existieren vor allem in den USA umfangreiche Untersuchungen [61]. 


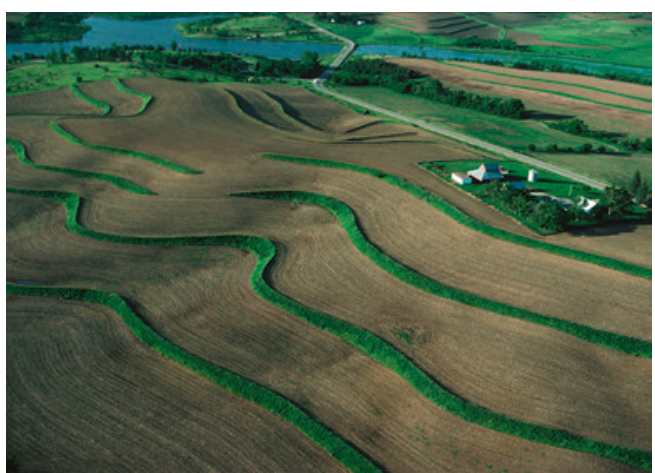

- Abb. 4.13 Wasser- und Stoffrückhalt in der Flur durch hanggliedernde Terrassenstufen mit einem zum Hang hin gerichteten Gefälle in den USA (Quelle: NRCS Gallery)

\subsubsection{Landwirtschaftliche Bewirtschaftungspraxis}

Die Möglichkeiten, innerhalb der ackerbaulichen Nutzung durch Bewirtschaftungsmaßnahmen die Abflusshöhe zu verringern, sind groß und lassen sich mithilfe des $\mathrm{CN}$-Verfahrens gut quantifizieren und planen. Dies soll hier an einem Beispiel gezeigt werden. Dabei wird von der hydrologischen Bodengruppe $\mathrm{C}$ und unterschiedlichen Feldfrüchten und Anbauverfahren ausgegangen. Der Bemessungsniederschlag soll im Februar $30 \mathrm{~mm}$ betragen und bis August linear auf $60 \mathrm{~mm}$ ansteigen, um dann wieder linear bis zum Februar auf $30 \mathrm{~mm}$ abzufallen (• Abb.4.14, Balkendiagramm). Als ungünstigster Fall wird von einer Maismonokultur ausgegangen, also dem wiederkehrenden Anbau von Mais ohne zwischengeschalteten Fruchtartenwechsel. Bei konventionell angebauter Maismonokultur ist die Abflussbildung von Winter bis Frühsommer hoch. Die Abflusshöhe beträgt 20 bis $24 \mathrm{~mm}$ (• Abb. 4.14, rote Linie). Sobald der Reihenschluss bei Mais im Sommer erreicht ist, infiltrieren dagegen selbst die hohen hier angenommenen Bemessungsniederschläge vollständig.

Ersetzt man die Hälfte des Maises und baut jedes zweite Jahr Wintergetreide an, wird der Jahresgang deutlich ausgeglichener (- Abb. 4.14, blaue Linie). Die Abflussneigung im Frühjahr und Frühsommer geht stark zurück, dafür steigt allerdings die Abflussneigung im Sommer und Herbst. In der Jahressumme ergibt sich kein Unterschied zwischen einer Maismonokultur und dieser Fruchtfolge. Bei ergiebigen Regenereignissen im Dezember kann die Fruchtfolge sogar etwas ungünstiger sein, da insbesondere der Winterweizen in dieser Zeit kaum den Boden bedeckt, der Bodenwasservorrat bereits wieder zu einem großen Teil aufgefüllt ist und der Saatbettzustand abflussanfälliger ist als ein gepflügtes Feld nach der Maisernte, bei dem der Bodenwasservorrat noch zu einem großen Teil entleert ist. Dennoch hat die Fruchtfolge gegenüber der Monokultur Vorteile, da sich dadurch eine Strukturierung der Landschaft ergibt (s. Abschn. 4.5.2). Auch treten im Winterhalbjahr die hohen Intensitätsspitzen normalerweise nicht auf, so dass in dieser Zeit zwar viel Abfluss möglich ist, die maximalen Abflussraten aber geringer bleiben als in den Sommermonaten.

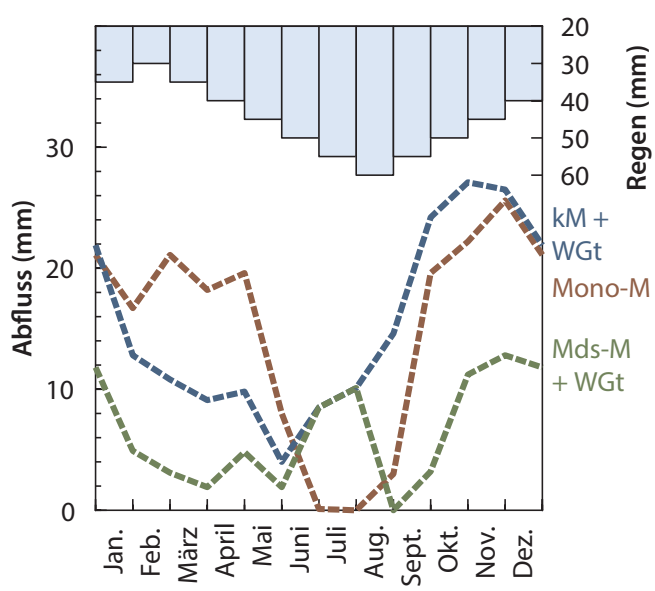

- Abb. 4.14 Jahresgang des Oberflächenabflusses von Monokultur-Mais (Mono-M), konventionell angebautem Mais und Wintergetreide im jährlichen Wechsel (kM + WGt) und eine Fruchtfolge aus Mulchdirektsaat-Mais und Wintergetreide (Mds-M + WGt). Die Werte gelten für die hydrologische Bodengruppe C. Der angenommene Jahresgang des Bemessungsregens ist als Balkendiagramm oben dargestellt 
Der Hauptvorteil der Fruchtfolge Mais-Wintergetreide liegt darin, dass nun Mulchdirektsaat des Maises möglich wird. Dabei wird nach dem Getreide eine abfrierende Winterzwischenfrucht (z. B. Senf) angebaut und der Mais im nächsten Jahr ohne Bodenbearbeitung in den abgefrorenen Senfbestand eingesät. Dies schließt insbesondere die Lücke der Bodenbedeckung im Winter, da ein dichter, wüchsiger Zwischenfruchtbestand bis in den Dezember hinein vorhanden ist. Durch die Direktsaat sind auch unmittelbar nach der Saat noch mindestens 30 \% Bodenbedeckung gegeben. Die Abflussmengen in den Wintermonaten halbieren sich und gleiches gilt für das Jahresmittel (• Abb. 4.14, grüne Linie).

Warum die Mulchdirektsaat so außerordentlich effizient ist, wird durch - Abb.4.15 illustriert. Sie zeigt den Senf, der nach Wintergetreide Ende Juli/Anfang August angebaut worden war und der sich zu dem Zeitpunkt im September bereits stark entwickelt hat und blüht, während der Mais im Hintergrund mindestens noch einen Monat bis zur Ernte benötigt. Dies bedeutet, dass es keine Lücke in der Bodenbedeckung gibt. Im Gegensatz zu allen überwinternden Ackerkulturen und selbst im Gegensatz zu

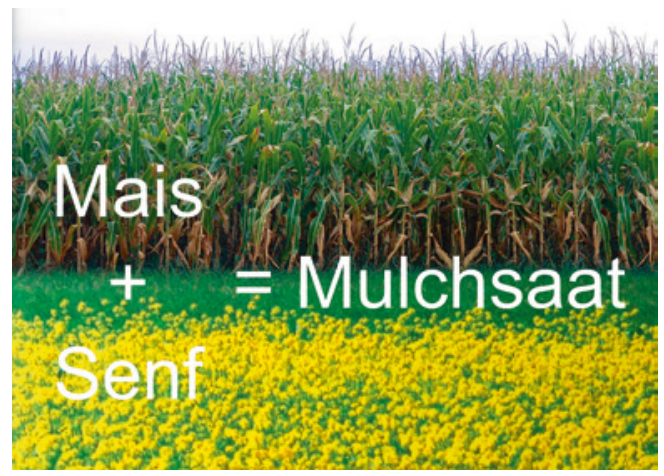

- Abb. 4.15 Illustration der Mulchsaat, die das zeitliche Hintereinander von Senf und Mais als räumliches Nebeneinander zeigt (Erläuterung s. Text); der Unterschied zwischen Mulchsaat und Mulchdirektsaat ist zu diesem Zeitpunkt (September) noch nicht zu sehen (Quelle: K. Auerswald)
Grünland und Wald liefert die abfrierende Zwischenkultur bis in den Dezember eine üppige, lebende Pflanzendecke. Erfolgt die Maissaat ohne Bodenbearbeitung („direkt“), bedeutet dies, dass der Boden mindestens 15 Monate von der Aussaat des Senfs bis zur Ernte des Maises nicht bearbeitet wird. Beim konventionellen Anbau bedecken dagegen alle Ackerkulturen - egal ob Getreide oder Reihenfrüchte - den Boden höchstens neun, manchmal sogar nur sechs Monate.

\section{Wirkungen der langen Bodenruhe bei}

\section{Mulchdirektsaat}

Die lange Zeit der Bodenruhe von deutlich über einem Jahr, bei der der Boden immer zu mehr als $30 \%$ bedeckt bleibt, löst eine Vielzahl von hydrologisch und hydraulisch bedeutsamen Veränderungen aus $[22,66]$ :

1. Die Regenwurmzahl steigt um $50 \%$.

Die Zahl der Regenwurmröhren in den obersten $5 \mathrm{~cm}$ des Bodens verfünffacht sich sogar, da sie nicht durch eine Bodenbearbeitung zerstört werden; sie bleiben hydraulisch wirksam.

2. Ohne Saatbettbereitung bleibt die Bodenbedeckung hoch. Dadurch kann die Bodenoberfläche nicht verschlämmen und behält ihre Infiltrationsfähigkeit; die Pfahlwurzel und der starke Stängel des (abgestorbenen) Senfs verhindern ein Aufschwimmen und Abschwemmen der Mulchdecke und schaffen biogene Grobporen.

3. Die Aggregatstabilität steigt; die sogenannte Perkolationsstabilität, die die Stabilität gegenüber plötzlicher Befeuchtung testet, verzehnfacht sich sogar. Auch dies schützt die Bodenoberfläche vor Verschlämmung und verhindert, dass an der Bodenoberfläche endende Regenwurmröhren durch Einschwemmen von Bodenteilchen verstopfen. 
4. Die Fließstrecke des Abflusses auf der Oberfläche erhöht sich, da Stängel und abgestorbene Pflanzenteile als Hindernis wirken. Gleichzeitig sinkt die Geschwindigkeit des Abflusses durch die höhere Rauheit der Mulchdecke. Dadurch steigt die Schichtdicke des Wassers auf der Bodenoberfläche. Wenn die Schichtdicke zwei Tropfendurchmesser erreicht (ca. $5 \mathrm{~mm}$ ), wirkt das Oberflächenwasser selbst als Mulch („Wassermulch“; [67, 68]), der die kinetische Energie der Regentropfen von der Bodenoberfläche abhält.

Mulchsaat, bei der die Reihenkultur nicht direkt, sondern mit einer leichten Bodenbearbeitung gesät wird, hat dagegen diese Vorzüge nicht. Sie verkürzt nur die Periode, in der der Boden unbedeckt bleibt, um etwa fünf Monate, da das Pflügen Ende Oktober/ Anfang November entfällt und die Bodenbearbeitung erst zur Saat (je nach Reihenkultur Ende März bis Ende April) erfolgt. Eine durchgehende Bodenruhe wird dadurch aber nicht erreicht.

Wegen der vorzüglichen Wirkung der Mulchdirektsaat würde die Abflussneigung nicht weiter sinken, sondern sogar steigen, wenn der Maisanteil in der Fruchtfolge auf unter $50 \%$ gesenkt würde. Dann wäre Mulchdirektsaat nicht mehr jedes zweite Jahr möglich. Gleiches gilt auch für den Bodenabtrag, der bei einer Fruchtfolge aus $50 \%$ Reihenkulturen und $50 \%$ Wintergetreide innerhalb der ackerbaulichen Möglichkeiten am geringsten ist, sofern die Reihenkulturen in Mulchdirektsaat mit einer Bodenbedeckung $>30 \%$ angebaut werden. Diese vorzügliche Wirkung der Mulchdirektsaat bei $50 \%$-igem Reihenkulturanteil hinsichtlich Abfluss- und Abtragsreduktion hat sich in langjährigen Abfluss- und Abtragsmessungen in kleinen Einzugsgebieten in
Scheyern bestätigt [69]. Trotz dieses enormen Potenzials für den Wasser- und Stoffrückhalt hat sich die Direktsaatvariante der Mulchsaat in der landwirtschaftlichen Praxis bislang wenig verbreitet [70].

Der Abfluss ließe sich noch weiter reduzieren, wenn der Anbau konturparallel erfolgen würde (• Abb.4.16, blaue Linie). Gerade große Flächen böten dazu die Möglichkeit. Allerdings sind die in Deutschland überwiegend verwendeten Landmaschinen, insbesondere der Wendepflug, für eine konturparallele Bewirtschaftung nicht geeignet, da sie den Kurven der Kontur nur schwer folgen können.

Bei konturparalleler Bewirtschaftung ließe sich auch noch eine Terrassierung etablieren, was den Abfluss weiter senken würde (-Abb.4.16, braune Linie). Alle Maßnahmen (Mulchdirektsaat, Konturnutzung und Terrassierung) zusammengenommen senken den Abfluss in den kritischen Monaten auf etwa ein Drittel und die Jahressumme sogar auf ein Viertel ab. Die Wirkung auf den Abflussscheitel ist noch weit höher, da alle drei Maßnahmen gleichzeitig auch die Fließgeschwindigkeit herabsetzten (s. Abschn. 7.3.5). Aus dem könnte gefolgert werden, dass eine Kontrolle von Sturzfluten einfach und allein mit Bewirtschaftungsmaßnahmen möglich wäre. Dies ist jedoch aus mehreren Gründen ein Trugschluss. Die Mulchdirektsaat erfordert hohes landwirtschaftliches Können, für den konturparallelen Anbau ist in Deutschland die Maschinenausstattung überwiegend nicht vorhanden und die Terrassierung ist eine Ingenieuraufgabe, die nur in umfangreichen Flur- und Bodenneuordnungsverfahren zu lösen wäre. Vor allem aber wurde in Abb. 4.5 gezeigt, dass Ackerflächen in den Sommermonaten nur etwa $20 \%$ bis $30 \%$ zum Gesamtabfluss beitragen. Zusätzliche Maßnahmen außerhalb der Ackerflächen sind daher unerlässlich. 


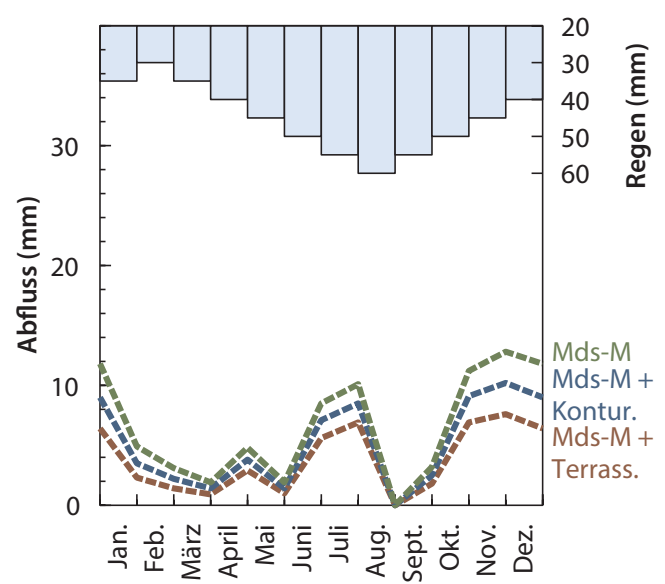

- Abb. 4.16 Simulierter Jahresgang des Oberflächenabflusses von abwechselnd MulchdirektsaatMais und Wintergetreide in Gefällerichtung (Mds-M), bei Konturnutzung (Mds-M + Kontur.) und bei Konturnutzung mit Terrassierung (Mds-M+Terrass.). Die Werte gelten für die hydrologische Bodengruppe $C$. Der angenommene Jahresgang des Bemessungsregens ist als Balkendiagramm oben dargestellt

Wirkungen des organischen Landbaus Für den organischen (ökologischen) Landbau ist Mulchdirektsaat keine Option, da im organischen Landbau chemische Unkrautbekämpfungsmittel nicht angewendet werden können und eine Unkrautkontrolle vor der Saat der Reihenkultur dort nur durch eine mechanische Bodenbearbeitung möglich ist. Der organische Landbau zeichnet sich dadurch aus, dass die Fruchtfolgen i. d. R. mehrjähriges Kleegras enthalten, da die Stickstofffixierung des Klees den Wegfall von Mineraldünger kompensieren muss. Kleegras ist wegen der durchgehenden Bedeckung günstiger als die anderen Ackerkulturen (vgl. CN-Werte in - Tab. 4.2). Vergleicht man die vorher verwendete konventionelle Mais-WintergetreideFruchtfolge mit einer typischen Fruchtfolge des organischen Landbaus aus zwei Jahren Kleegras, einem Jahr einer Reihenkultur und zwei Jahren Wintergetreide, so zeigt sich in der Modellierung, dass durch die vielfältigere Fruchtfolge der Jahresgang der Abflussbildung noch ausgeglichener wird (• Abb. 4.17, braune Linie).

Insbesondere die hohe Abflussneigung von Winter bis Frühsommer wird durch das Kleegras gemildert. Dies stimmt auch mit Erfahrungen aus der Literatur überein: Eine umfassende Literaturauswertung [71] ergab, dass in etwa $40 \%$ der Fälle der organische Landbau zu weniger Abfluss führte als der konventionelle, in weiteren $40 \%$ trat kein Unterschied auf und in ca. $20 \%$ der Fälle war der Abfluss im organischen Landbau höher. Es muss allerdings angeführt werden, dass sich der organische Landbau mit dem CN-Verfahren nur eingeschränkt abbilden lässt. Insbesondere werden mögliche Nachwirkungen des Kleegrases in den folgenden Jahren, z. B. eine erhöhte Aggregatstabilität (s. [71, 72]), in • Tab. 4.2 nicht berücksichtigt, da sie nicht beim Kleegras selbst auftreten, sondern bei den Folgekulturen. Die Ergebnisse von [18] deuten darauf hin, dass die CN-Werte in den Kulturen, die auf mehrjähriges Kleegras folgen, niedriger sind als bei anderen Vorfrüchten. Allerdings hatten die Autoren mineralisch gedüngte Systeme untersucht [18]. Auch ist unklar, ob sich das geringere Ertragsniveau der Kulturen auswirkt und zu höheren CN-Werten führt. Diese Einschränkung ist allerdings kein Mangel des CN-Verfahrens selbst, sondern liegt nur daran, dass die für die Parametrisierung notwendigen Daten für den organischen Landbau nicht erhobenen wurden. Auch wurde der organische Landbau hinsichtlich seiner Umweltwirkungen wie der Bildung von Oberflächenabfluss kaum optimiert, sondern es wird nur allgemein davon ausgegangen, dass er besser ist als der konventionelle Anbau. Daher ist auch nicht verwunderlich, wenn er gegenüber einem in dieser Hinsicht optimierten Verfahren wie der Mulchdirektsaat zurückfällt. 


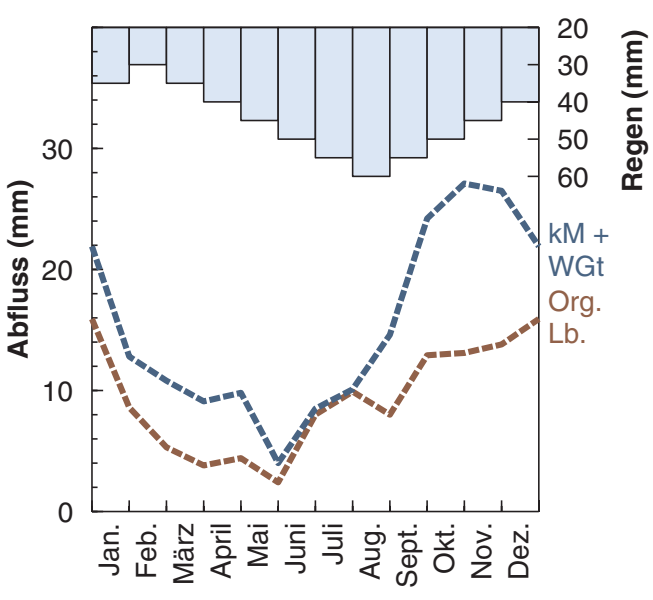

- Abb. 4.17 Vergleich des Jahresgangs des Oberflächenabflusses bei konventionellem Anbau einer Fruchtfolge mit 50 \% Mais und 50 \% Wintergetreide $(\mathrm{kM}+\mathrm{WGt})$, mit einer typischen fünffeldrigen Fruchtfolge des organischen Landbaus, mit zwei Kleegrasjahren (Org. Lb.). Die Werte gelten für die hydrologische Bodengruppe $C$. Der angenommene Jahresgang des Bemessungsregens ist als Balkendiagramm oben dargestellt. Mögliche Effekte durch Runon-Infiltration sind nicht berücksichtigt

\section{Literatur}

1. Linsley RK, Kohler MA, Paulhus JLH (1949) Applied Hydrology. McGraw-Hill, New York

2. Becker, A. (1964) Starkregen-Abfluß-Beziehung in Form einer koaxialen graphischen Darstellung zur Vorherbestimmung des Starkregenabflusses aus einem kleinen Einzugsgebiet der DDR. Wasserwirt Wassertechnik 14(4):120-125

3. Horton RE (1939) Analysis of runoff-plot experiments with varying infiltration-capacity. Trans Am Geophys Union 20:693. > https://doi.org/10.1029/ TR020i004p00693

4. Lutz W (1984) Berechnung von Hochwasserabflüssen unter Anwendung von Gebietskenngrößen. Mitt Inst Hydrol Wasserwirt 24: Universität Karlsruhe

5. Natural Resources Conservation Service (2004) Estimation of direct runoff from storm rainfall. In: National Engineering Handbook. Part 630 Hydrology, chapter 10. US Department of Agriculture, Washington

6. Williams JR, Kannan N, Wang X, Santhi C (2012) Evolution of the SCS runoff curve number method and its application to continuous runoff simulation. J Hydrol Eng 17:1221-1229
7. Kleeberg R-B, Overland H (1989) Zur Berechnung des effektiven oder abflusswirksamen Niederschlags. Mitt Inst Wasserwesen 32: Universität der Bundeswehr München, Neubiberg

8. Auerswald K, Haider J (1996) Runoff curve numbers for small grain under German cropping conditions. J Environ Manag 47:223-228

9. Fiener P, Auerswald K (2006) Influence of scale and land use pattern on the efficacy of grassed waterways to control runoff. Ecol Eng 27:208-218. - https://doi.org/10.1016/j.ecoleng.2006.02.005

10. Deutscher Verband für Wasserwirtschaft und Kulturbau (1982) Arbeitsanleitung zur Anwendung von Niederschlag-Abfluß-Modellen in kleinen Einzugsgebieten. Teil I: Analyse. Regeln zur Wasserwirtschaft 112: Paul Parey, Hamburg

11. Deutscher Verband für Wasserwirtschaft und Kulturbau (1984) Arbeitsanleitung zur Anwendung von Niederschlag-Abfluß-Modellen in kleinen Einzugsgebieten. Teil II: Synthese. Regeln zur Wasserwirtschaft 113: Paul Parey, Hamburg

12. Merz $R$ (2006) Regionalisierung von Ereignisgrößen. In: Blöschl G, Godina R, Merz R (Hrsg) Methoden der hydrologischen Regionalisierung. Wiener Mitt 197:179-194 Technische Universität, Wien

13. Deutscher Verband für Wasserwirtschaft und Kulturbau (1999) Hochwasserabflüsse. Schriften 124: Wirtschafts- und Verlagsgesellschaft Gas und Wasser, Bonn

14. Patt H, Jüpner R (2013) Hochwasser-Handbuch, Auswirkungen und Schutz. Springer, Berlin

15. Ponce VM, Hawkins RH (1996) Runoff curve number: has it reached maturity? J Hydrol Eng 1:11-19

16. Merz R, Blöschl G (2009) A regional analysis of event runoff coefficients with respect to climate and catchment characteristics in Austria. Water Resour Res 45:1-19. https://doi. org/10.1029/2008WR007163

17. Arnold JG, Williams JR, Nicks AD, Sammons DB (1990) SWRRB - a basin scale simulation model for soil and water resources management. Texas A \& M University Press, College Station

18. Bonta JV, Shipitalo MJ (2013) Curve numbers for long-term no-till corn and agricultural practices with high watershed infiltration. J Soil Water Conserv 68:487-500. https://doi.org/10.2489/jswc. 68.6.487. https://doi.org/10.2489/jswc.68.6.487

19. Elhakeem M, Papanicolaou AN (2009) Estimation of the runoff curve number via direct rainfall simulator measurements in the state of lowa, USA. Water Resour Manag 23:2455-2473. > https://doi. org/10.1007/s11269-008-9390-1 
20. Auerswald K (1985) Erosionsgefährdung unter Zuckerrüben und Sommergerste. J Agron Crop Sci 155:34-42

21. Auerswald K (1985) Beurteilung der Erosionsanfälligkeit von Mais bei unterschiedlichen Anbauverfahren. J Agron Crop Sci 154:45-55

22. Kainz M (1989) Runoff, erosion and sugar beet yields in conventional and mulched cultivation. Soil Technol Ser 1:103-114

23. Haider J (1994) Herbizide in Oberflächenabfluß und Bodenabtrag - Feldversuche mit simulierten Regen. Dissertation, Technische Universität, München

24. Schwertmann U, Vogl W, Kainz M (1987) Bodenerosion durch Wasser - Vorhersage des Bodenabtrags und Bewertung von Gegenmaßnahmen. Ulmer, Stuttgart

25. Deutsches Institut für Normung (2017) Bodenbeschaffenheit - Ermittlung der Erosionsgefährdung von Böden durch Wasser mit Hilfe der ABAG. DIN 19708:2017-08; Beuth Verlag, Berlin

26. Seibert SP, Jackisch C, Pfister L, et al (2016) Exploring the interplay between state, structure and runoff behavior of lower mesoscale catchments. Hydrol Earth Syst Sci Discuss 1-51. - https://doi.org/10.5194/hess-2016-109

27. Markart G, Kohl B, Sotier B, et al (2004) Provisorische Geländeanleitung zur Abschätzung des Oberflächenabflussbeiwertes auf alpinen Boden-/Vegetationseinheiten bei konvektiven Starkregen. BFW-Dokumentation 4: Bundesamt und Forschungszentrum Wald. Wien

28. Tempel M (2006) Abflussverhalten kleiner, forstlich genutzter Bacheinzugsgebiete am Beispiel des Einzugsgebietes des Oberen Gräfenbaches im Soonwald/Hunsrück. Dissertation, Johannes Gutenberg-Universität, Mainz

29. Fox DM, Bryan RB, Price AG (1997) The influence of slope angle on final infiltration rate for interrill conditions. Geoderma 80:181-194. $>$ https://doi. org/10.1016/S0016-7061(97)00075-X

30. Poesen J (1984) The influence of slope angle on infiltration rate and Hortonian overland flow volume. Z Geomorph Suppl 49:117-131

31. Poesen J (1986) Surface sealing as influenced by slope angle and position of simulated stones in the top layer of loose sediments. Earth Surf Process Landforms 11:1-10. $>$ https://doi. org/10.1002/esp.3290110103

32. Bayerisches Landesamt für Umwelt (2016) Loseblattsammlung Hydrologische Planungsgrundlagen. Augsburg

33. Landesanstalt für Umweltschutz BadenWürttemberg (2005) Festlegung des Bemessungshochwassers für Anlagen des technischen Hochwasserschutzes. Karlsruhe
34. Maniak U (2016) Hydrologie und Wasserwirtschaft. Springer, Berlin

35. Junghänel $T$, Ertel $H$, Deutschländer $T$ (2017) KOSTRA-DWD-2010R. Bericht zur Revision der koordinierten Starkregenregionalisierung und -auswertung des Deutschen Wetterdienstes in der Version 2010. Deutscher Wetterdienst, Offenbach am Main

36. Milly PCD, Wetherald RT, Dunne KA, Delworth TL (2002) Increasing risk of great floods in a changing climate. Nature 415:514-517. https://doi. org/10.1038/415514a

37. Milly PCD, Betancourt J, Falkenmark M et al (2008) Stationarity is dead: whither water management? Science 319:573-574. > https://doi.org/10.1126/ science. 1151915

38. Bayerisches Landesamt für Umwelt (2013) Amtliche Festsetzung von Überschwemmungsgebieten in Bayern. Informationsdienst Überschwemmungsgefährdete Gebiete. > https:// www.Ifu.bayern.de/wasser/hw_ue_gebiete/ informationsdienst/index.htm

39. Landesanstalt für Umwelt, Messungen und Naturschutz Baden-Württemberg (2016) Leitfaden Kommunales Starkregenrisikomanagement in Baden-Württemberg. Karlsruhe

40. Deutscher Wetterdienst (2017) Raster der Wiederkehrintervalle für Starkregen (Bemessungsniederschläge) in Deutschland (KOSTRA-DWD), Version 2010R. Climate Data Center, Offenbach am Main

41. Deutscher Wetterdienst (2018) RADKLIM. Erstellung einer radargestützten hochaufgelösten Niederschlagsklimatologie für Deutschland zur Auswertung der rezenten Änderungen des Extremverhaltens von Niederschlag. Beschreibung des Kompositformats und der verschiedenen Reprozessierungsläufe. Offenbach am Main

42. Winterrath T, Brendel C, Hafer M, et al. (2018) RADKLIM Version 2017.002: Reprocessed quasi gauge-adjusted radar data, 5-minute precipitation sums (YW). > https://doi.org/10.5676/dwd/ radklim_yw_v2017.002, Offenbach am Main

43. Fischer FK, Winterrath T, Auerswald K (2018) Temporal- and spatial-scale and positional effects on rain erosivity derived from point-scale and contiguous rain data. Hydrol Earth Syst Sci 22:6505-6518. > https://doi.org/10.5194/hess-226505-2018

44. Allen RJ, DeGaetano AT (2005) Areal reduction factors for two eastern United States regions with high rain-gauge density. J Hydrol Eng 10:327335 . https://doi.org/10.1061/(ASCE)10840699(2005)10:4(327)

45. Asquith W, Famiglietti J (2000) Precipitation arealreduction factor estimation using an annualmaxima centered approach. J Hydrol 230:55-69. - https://doi.org/10.1016/S0022-1694(00)00170-0 
46. De Michele C, Rosso R (2002) A multi-level approach to flood frequency regionalisation. Hydrol Earth Syst Sci 6:185-194

47. Rieger W (2012) Prozessorientierte Modellierung dezentraler Hochwasserschutzmaßnahmen. Mitt Inst Wasserwesen Wasserwirt Ressourcenschutz 116: Universität der Bundeswehr München, Neubiberg

48. Achilles W (1993) Deutsche Agrargeschichte im Zeitalter der Reformen und der Industrialisierung. Eugen Ulmer, Stuttgart

49. Sächsisches Landesamt für Umwelt, Landwirtschaft und Geologie (2015) Begrünung von erosionsgefährdeten Abflussbahnen. Dresden

50. Auerswald K (2019) Grünlandverlust - Ursachen und Wirkungen. Schriftenr Bayer Landesanst Landwirtsch 6:17-20, Freising

51. Fiener P, Auerswald K, Van Oost K (2011) Spatio-temporal patterns in land use and management affecting surface runoff response of agricultural catchments - a review. Earth-Science Rev 106:92-104. > https://doi.org/10.1016/j. earscirev.2011.01.004

52. Woolhiser DA, Smith RE, Giraldez JV (1996) Effects of spatial variability of saturated hydraulic conductivity on Hortonian overland flow. Water Resour Res 32:671-678

53. Corradini C, Morbidelli R, Melone F (1998) On the interaction between infiltration and Hortonian runoff. J Hydrol 204:52-67. https://doi. org/10.1016/S0022-1694(97)00100-5

54. Auerswald K, Schröder R (2001) Simulation von verschlämmungsgesteuertem Abfluss heterogen genutzter Einzugsgebiete. Wasser Boden 53:17-20

55. European Commission (2015) Strip cropping along contours. Natural waters retention measures. www.nwrm.eu

56. Wischmeier WH, Smith DD (1978) Predicting rainfall erosion losses: a guide to conservation planning. Agricult Handb 537: US Department of Agriculture. Washington

57. Kistler M, Brandhuber R, Maier H (2013) Wirksamkeit von Erosionsschutzmaßnahmen, Ergebnisse einer Feldstudie. Schriftenr Bayer Landesanst Landwirtsch 8: Freising

58. Fiener P, Auerswald K (2005) Measurement and modeling of concentrated runoff in grassed waterways. J Hydrol 301:198-215. https://doi. org/10.1016/j.jhydrol.2004.06.030

59. Bayerisches Landesamt für Statistik (2015) Landwirtschaftlich genutzte Fläche seit 1960 nach Nutzungsarten. Fürth

60. van der Ploeg RR, Ehlers W, Sieker F (1999) Floods and other possible adverse environmental effects of meadowland area decline in former West Germany. Naturwissenschaften 86:313-319. - https://doi.org/10.1007/s001140050623

61. Natural Resources Conservation Service (2011) Terraces. In: Engineering Field Handbook. Part 650, chapter 8. US Department of Agriculture, Washington

62. Zhao J, Van Oost K, Chen L, Govers G (2016) Moderate topsoil erosion rates constrain the magnitude of the erosion-induced carbon sink and agricultural productivity losses on the Chinese Loess Plateau. Biogeosciences 13:47354750. https://doi.org/10.5194/bg-13-4735-2016

63. Luft G, Vogelbacher A (1985) Modellrechnungen zum Einfluß von Großterrassierungen auf den Abflußprozeß. Z Kulturtechnik Flurberein 26:1-12

64. Vogelbacher A (1985) Simulation der Wasserbilanz in terrassierten Lößgebieten. Beiträge zur Hydrologie, Kirchzarten

65. Kováŕ P, Bačinová $H$, Loula J, Fedorova D (2016) Use of terraces to mitigate the impacts of overland flow and erosion on a catchment. Plant, Soil Environ 62:171-177. $>$ https://doi. org/10.17221/786/2015-PSE

66. Schneider A-K, Hohenbrink TL, Reck A et al (2018) Variability of earthworm-induced biopores and their hydrological effectiveness in space and time. Pedobiologia 71:8-19. $>$ https://doi.org/10.1016/J. PEDOBI.2018.09.001

67. Palmer RS (1964) The influence of a thin water layer on waterdrop impact forces. IAHS Publ 65:141-148

68. Mutchler CK, Hansen LM (1970) Waterdrop at terminal velocity. Science 169:1311-1312

69. Auerswald K, Albrecht H, Kainz M, Pfadenhauer J (2000) Principles of sustainable land-use systems developed and evaluated by the Munich research alliance on agro-ecosystems (FAM). Petermanns Geogr Mitt 144:16-25

70. Auerswald K, Fischer FK, Kistler M et al (2018) Behavior of farmers in regard to erosion by water as reflected by their farming practices. Sci Total Environ 613-614:1-9. \ https://doi.org/10.1016/j. scitotenv.2017.09.003

71. Thünen-Institut (2019) Leistungen des ökologischen Landbaus für Umwelt und Gesellschaft. Thünen-Report 65: Braunschweig

72. Auerswald K, Kainz M, Fiener P (2003) Soil erosion potential of organic versus conventional farming evaluated by USLE modelling of cropping statistics for agricultural districts in Bavaria. Soil Use Manag 19:305-311. > https://doi. org/10.1111/j.1475-2743.2003.tb00320.x 
Open Access Dieses Kapitel wird unter der Creative Commons Namensnennung 4.0 International Lizenz ( $\triangleright$ http://creativecommons.org/licenses/by/4.0/deed.de) veröffentlicht, welche die Nutzung, Vervielfältigung, Bearbeitung, Verbreitung und Wiedergabe in jeglichem Medium und Format erlaubt, sofern Sie den/ die ursprünglichen Autor(en) und die Quelle ordnungsgemäß nennen, einen Link zur Creative Commons Lizenz beifügen und angeben, ob Änderungen vorgenommen wurden.

Die in diesem Kapitel enthaltenen Bilder und sonstiges Drittmaterial unterliegen ebenfalls der genannten Creative Commons Lizenz, sofern sich aus der Abbildungslegende nichts anderes ergibt. Sofern das betreffende Material nicht unter der genannten Creative Commons Lizenz steht und die betreffende Handlung nicht nach gesetzlichen Vorschriften erlaubt ist, ist für die oben aufgeführten Weiterverwendungen des Materials die Einwilligung des jeweiligen Rechteinhabers einzuholen. 